https://doi.org/10.31713/m1113

\title{
SUBSTANTIATION OF RATIONAL PARAMETERS OF THE EXPLOSIVE BREAKOUT TECHNOLOGY IN A STRUCTURAL BLOCK ARRAY
}

Yelzhanov Yerbol Abdrakhmanovich

International Educational Corporation LLP (Kazakh Main Architectural and Construction Academy), Candidate of Technical Sciences, Associate Professor, Republic of Kazakhstan Deputy Dean for External Relations and Student Affairs

\section{Yussupova Saltanat Abenovna}

Almaty University of Power Engineering and Telecommunications named after Gumarbek Daukeyev, Candidate of Technical Sciences, associate professor, Republic of Kazakhstan

\author{
Aben Yerbolat Khalidillaevich \\ Candidate of Technical Sciences, associate professor of Mining \\ department, Satbayev University, Republic of Kazakhstan
}

\section{Annotation}

The idea of this work is to choose a technological scheme of drilling and blasting, which provides spacer pinching of the separateness released along the natural surfaces of the weakening of the ore massif and thereby increases the duration and efficiency of explosive crushing of the structural block array as a whole, the object of research of which is the technological process of drilling and blasting of ore during underground mining of powerful and medium-capacity deposits represented by strong ores.

The authors in this robot investigated the parameters of fracturing and structural blockiness of the ore-containing massif of the Yubileynoye deposit and conducted experimental work to establish the quality of breaking of the fractured structural block ore array, and also developed recommendations for choosing a rational scheme and calculating the parameters of drilling and blasting operations in a structurally heterogeneous array.

Keywords: Ore extraction, Drilling and blasting, Underground mining of deposits

\section{Introduction}

Currently, the annual volume of world mining has exceeded 10 billion tons, of which about $64 \%$ are solid minerals. An analysis of the dynamics of production volumes over the past 20 years shows that the specific increase in the gross output of the mining industry in the Asian economy is the largest today and during this time it has 
increased almost one and a half times, while in European countries and in North America this indicator is noticeably decreasing. It should be noted that the volume of mining operations in Africa, Australia and South America is also characterized by significant growth.

The demand for mineral raw materials and metals in the world due to scientific and technological progress is constantly growing. At the same time, the explored balance reserves of ore deposits are rapidly decreasing, the mining and geological conditions of the remaining reserves and the mining conditions of their development are deteriorating, the content of useful components is noticeably decreasing.

The development of mineral resources in a market economy requires the creation of new efficient development systems, the use of machines and mechanisms with high productivity, reliability, energy conservation, as well as their equipment with advanced mechanization and automation systems.

Integrated use of mineral resources, reduction of costs during sinking and cleaning operations, reduction of mineral losses, as well as ensuring the safety of people require rational mining operations in full compliance with the mining and geological and mining engineering conditions for the development of mineral deposits.

When drawing up mining schedules and passports of drilling and blasting operations, along with the results of standard laboratory studies of the physical and technical properties of rock samples, it is necessary to study the structure of the massif in detail. This is due to the fact that the consumption of explosives in an array disturbed by crack systems can be noticeably reduced. In addition, the incorrect orientation of the charges of boreholes and boreholes relative to the position of the dominant system of cracks leads to dislocations associated with the violation of rocks in the legal zone of mining. Therefore, along with the structural attenuation coefficient, traditionally taken into account in calculations, it is necessary to pay attention to the orientation of crack systems in the face.

The degree and nature of fracturing of rocks in the massif, the orientation and level of the main natural stresses, the choice of the optimal layout of blast wells and their blasting mode have a significant impact on the results of the explosion.

In connection with the above, the choice of an effective technology 


\section{Investigation of the structure of the ore massif and assess-}

ment of its impact on the technology and parameters of drilling and blasting operations

\subsection{Determination of fracturing parameters of the ore- containing array}

To assess the structural structure of the array using the amplitude parameters of passing elastic waves, experimental observations were carried out in underground conditions according to the scheme shown in Fig. 1.

Calibrated charges of ammonite № 6 weighing $125 \mathrm{~g}$ were used as a pulse source, the detonation of which was initiated by electric detonators. The charges were placed in holes drilled at various distances from the sensor installation site, as shown in Figure 1. The recording equipment was the SMV, VIB-A seismic receivers and the P-700 oscilloscope. The seismic receivers were mounted on the wall of the mine using a solution of fast-hardening cement and recorded the horizontal component of the vibration velocity of the free surface, which is associated with the mass velocity of particles at the wave front passing through the array.

Calibration of VIB-A vibrographs was carried out in accordance with the instructions set out in the instrument passport; SMV seismic receivers were calibrated on a vibration stand according to the VNIMI methodology given in [1].

In the monograph by E.F. Savarensky and D.P. Kirnos, it is shown that when choosing sensors to obtain undistorted signal recording, two fundamentally different approaches are possible, which follow from the solution of the differential equation describing the operation of the seismograph.

1 The natural oscillation frequency of the moving part of the device should be much less than the frequency of the recorded process. In this mode, vibragraphs work to record the amplitudes and velocities of vibrations.

2 The natural oscillation frequency of the moving part of the device should be much higher than the natural frequency of the recorded process. In this mode, sensors work to record the accelerations of vibrations.

Calibration of the sensors determined that the natural oscillation frequency of the moving part of the VIB-A seismic receiver is $2 \mathrm{~Hz}$, 
and for the CMV device - $20 \mathrm{~Hz}$, and the sensitivity is $10.8 \mathrm{mV} *$ $\mathrm{s} / \mathrm{cm}$ and $31.2 \mathrm{mV} / \mathrm{cm}$, respectively. The sensitivity of the seismic receivers was determined at frequencies of $300-500 \mathrm{~Hz}$.

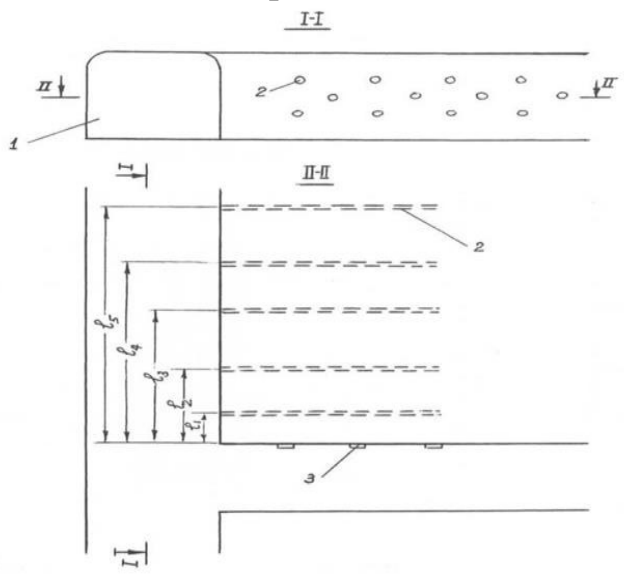

Fig. 1. Layout of calibrated explosive charges and seismic receivers for measuring the velocities of longitudinal waves in a structural block array: 1 - sub - storey drift; 2 - holes with calibrated explosive charges; 3 - seismic receivers

By analyzing the frequency of vibrations of the rock mass received by the seismic receiver, it was found that the predominant frequency of the voltage wave pulse excited by the explosion based on measurements of $0.25-7.05 \mathrm{~m}$ or at relative distances $(12-352) \cdot r_{0}$, where $r_{0}$ is the radius of the explosive charge used, was exactly $300-500 \mathrm{~Hz}$.

The seismic sensors used high-frequency galvanometers M 001.5 with an operating frequency band from 0 to $1700 \mathrm{~Hz}$. As indicated in [2], when using a high-frequency galvanometer, the frequency of free oscillations of which is much higher than the frequency of the recorded process, the deflection of the beam to the seismic receiver will be proportional to the magnitude of the current flowing through the coil. Thus, in our conditions, a low-frequency sensor paired with a broadband galvanometer is able to give an undistorted diagram of the speed of the observed oscillations.

In the course of experimental work, 25 experimental explosions were made. A well - known dependency was used to decipher the received signals

$$
v=\frac{A \cdot R_{о б}}{j_{r} \cdot j_{c}},
$$


where $v$ - displacement velocity, $\mathrm{m} / \mathrm{s}$;

$A$ - the amplitude of the displacement on the oscillogram, mm;

$R_{o \sigma}$ - the resistance of the circuit, which consists of the resistance of the seismic receiver, the resistance of the wires and the internal resistance of the galvanometers, ohms;

$j_{r}$ - galvanometer sensitivity, $\mathrm{mm} / \mathrm{mA}$;

$j_{c}$ - sensitivity of the seismic receiver, $\mathrm{MB} \cdot \mathrm{c} / \mathrm{cm}$.

The values of the displacement velocities were taken according to the amplitude of the first entry, which was the maximum in all records. In the studied range of changes in the distances from the explosion source to the signal registration point, the first entry on the seismic receivers is the result of the passage of a direct voltage wave.

Table 1 shows the results of measurements of the displacement rates of the outcrop surface of the rock mass at various distances from the source of the explosion and the results of calculations of the amplitude parameters of fracturing.

The data were processed by methods of mathematical statistics, the boundaries of confidence intervals were found for the distributions, standard deviations and coefficients of variation were calculated [3-5]. The standard deviation for the amplitude fracture indices was 0.09 , and the coefficient of variation was $25 \%$.

The study of the effect of fracturing on the parameters of elastic waves was carried out within the sub-storey workings at the horizons of 345 and $331 \mathrm{~m}$, where rocks are mainly granite porphyry. Before the start of the explosions, a sketch was carried out of all visible traces of cracks on the outcrops of the massif with the measurement of their width, azimuths of strike and angles of incidence. Visual observations and measurements have established that the rocks in the studied areas are characterized by intense fracturing. The width of the cracks varies from 0.5 to $2 \mathrm{~mm}$. When processing the data, the total number of cracks along the measurement lines was calculated and the average size of the natural separations composing the array was determined. The average size of natural isolation on mountains. $345 \mathrm{~m}$ is 25 $\mathrm{cm}$, and on mountains. $331 \mathrm{~m}-32 \mathrm{~cm}$. At the same time, the nature of the cracks - their length and width on both horizons remain the same.

The amplitude index of fracturing is equal to the ratio of the amplitude of the wave passing in the fractured array to the amplitude of the wave in the monolith at the same distance. The values of the amplitudes $A_{1}$ and $A_{2}$ were determined experimentally by detonating calibrated charges weigh- 
ing $125 \mathrm{~g}$ in natural separations of different lengths. The absorption coefficient for monolithic rocks turned out to be equal.

Table 1

Results of measurement of elastic wave parameters in fractured rocks

\begin{tabular}{|c|c|c|c|c|c|c|c|c|c|c|}
\hline \multirow{2}{*}{ № } & \multirow{2}{*}{$\begin{array}{l}\text { Distance } \\
\text { to the } \\
\text { explo- } \\
\text { sion } \\
\text { point, } \\
\mathrm{cm}\end{array}$} & \multirow{2}{*}{$\begin{array}{c}\text { Measured } \\
\text { displace- } \\
\text { ment } \\
\text { velocity, } \\
\mathrm{cm} / \mathrm{s}\end{array}$} & \multirow{2}{*}{$\begin{array}{l}\text { Estimated } \\
\text { displace- } \\
\text { ment } \\
\text { velocity for } \\
\text { monolithic } \\
\text { rock, } \mathrm{cm} / \mathrm{s}\end{array}$} & \multirow{2}{*}{$\begin{array}{l}\text { The } \\
\text { ampli- } \\
\text { tude } \\
\text { index of } \\
\text { fractur- } \\
\text { ing, the } \\
\text { fraction } \\
\text { is one. }\end{array}$} & \multicolumn{2}{|c|}{$\begin{array}{l}\text { The number of } \\
\text { cracks in the } \\
\text { measurement } \\
\text { interval, pcs. }\end{array}$} & \multicolumn{2}{|c|}{$\begin{array}{l}\text { The size of the natural } \\
\text { part, } \mathrm{cm}\end{array}$} & \multicolumn{2}{|c|}{$\begin{array}{c}\text { Deviatio } \\
\mathrm{n}\end{array}$} \\
\hline & & & & & $\begin{array}{c}\text { actua } \\
1\end{array}$ & $\begin{array}{c}\text { Settleme } \\
\mathrm{nt}\end{array}$ & $\begin{array}{c}\text { Measure } \\
\mathrm{d}\end{array}$ & $\begin{array}{c}\text { calculate } \\
\text { d }\end{array}$ & $\begin{array}{l}\mathrm{c} \\
\mathrm{m}\end{array}$ & $\%$ \\
\hline 1 & 2 & 3 & 4 & 5 & 6 & 7 & 8 & 9 & 10 & $\begin{array}{l}1 \\
1\end{array}$ \\
\hline \multicolumn{11}{|c|}{ horizon $345 \mathrm{~m}$} \\
\hline 1 & 45 & 130,0 & 158,4 & 0,82 & 2 & 2 & 22 & 20 & 2 & 9 \\
\hline 2 & 60 & 115,4 & 116,0 & 0,99 & 2 & 2 & 25 & 26 & 1 & 4 \\
\hline 3 & 90 & 70,8 & 78,3 & 0,90 & 4 & 4 & 20 & 24 & 4 & 20 \\
\hline 4 & 108 & 52,3 & 63,8 & 0,82 & 4 & 4 & 25 & 22 & 3 & 12 \\
\hline 5 & 118 & 52,0 & 58,7 & 0,88 & 5 & 5 & 20 & 15 & 5 & 25 \\
\hline 6 & 128 & 40,9 & 53,6 & 0,76 & 5 & 5 & 26 & 22 & 4 & 15 \\
\hline 7 & 152 & 38,3 & 50,4 & 0,76 & 6 & 6 & 21 & 18 & 3 & 14 \\
\hline 8 & 162 & 23,8 & 40,2 & 0,57 & 6 & 6 & 23 & 19 & 4 & 17 \\
\hline 9 & 165 & 26,4 & 38,3 & 0,69 & 7 & 6 & 26 & 24 & 2 & 8 \\
\hline 10 & 181 & 23,2 & 34,5 & 0,67 & 7 & 7 & 28 & 24 & 4 & 14 \\
\hline 11 & 180 & 23,6 & 34,5 & 0,68 & 7 & 7 & 28 & 24 & 4 & 14 \\
\hline 12 & 188 & 20,0 & 33,0 & 0,60 & 7 & 8 & 27 & 25 & 3 & 11 \\
\hline
\end{tabular}

horizon $331 \mathrm{~m}$

\begin{tabular}{l|l|l|l|l|l|l|l|l|l|l}
\hline 1 & 50 & 127,9 & 130,5 & 0,98 & 1 & 1 & 25 & 25 & 0 & 0 \\
2 & 65 & 106,6 & 107,8 & 0,99 & 2 & 1 & 27 & 31 & 4 & 15 \\
3 & 158 & 30,6 & 40,2 & 0,76 & 6 & 6 & 20 & 22 & 2 & 10 \\
4 & 169 & 24,0 & 38,2 & 0,63 & 6 & 9 & 24 & 17 & 7 & 29 \\
5 & 180 & 23,5 & 34,0 & 0,69 & 6 & 7 & 25 & 22 & 3 & 12 \\
6 & 305 & 8,9 & 13,2 & 0,67 & 9 & 8 & 31 & 34 & 3 & 10 \\
7 & 312 & 8,0 & 13,0 & 0,62 & 9 & 9 & 30 & 31 & 1 & 3 \\
8 & 320 & 7,2 & 11,9 & 0,61 & 9 & 9 & 32 & 32 & 0 & 0 \\
9 & 540 & 1,4 & 2,8 & 0,50 & 13 & 13 & 36 & 38 & 2 & 5 \\
10 & 550 & 1,2 & 2,7 & 0,44 & 13 & 14 & 39 & 36 & 3 & 8 \\
11 & 685 & 0,6 & 1,2 & 0,50 & 15 & 13 & 43 & 49 & 6 & 14 \\
12 & 703 & 0,4 & 1,0 & 0,40 & 15 & 16 & 44 & 42 & 2 & 4 \\
13 & 705 & 0,4 & 1,0 & 0,40 & 15 & 16 & 44 & 42 & 2 \\
\hline
\end{tabular}

Fig. 2 shows a graph of the dependence of the amplitude index of fracturing on the number of cracks in the path of the wave, based on 
the results of measurements on both horizons. This dependence is approximated by the following equation

$$
\frac{A_{i}}{A_{M}}=\frac{1}{1+Q N}=\frac{1}{1+0,08 N} .
$$

It is noteworthy that the values of the ratios of the amplitude indices of fracturing $-A_{i} / A_{M}$, obtained at sites with different sizes of "natural separations and at different distances from the explosion point are described by one equation. This confirms the conclusions made as a result of laboratory experiments about the fundamental possibility of assessing the structural state of the array by the ratio $A_{i} / A_{M}$.

In general, the dependence $\left(A_{i} / A_{M}\right)=f(a, N)$ can be represented by a family of curves of the form $1 /(1+a N)$ with different coefficient values $a$, which indirectly characterizes the qualitative characteristics of cracks - their width and type of filler. The greater the width of the cracks and the difference in wave resistances when passing through the cracks and "separately", the greater the value $a$ and steeper than a parabola.

Based on formula (2), using the values of the amplitudes $\mathrm{Ai}$ measured at a certain distance $r$ from the explosion point, it is possible to calculate the number of cracks at this distance and then calculate the average size of the "natural" separation.

Table 2

Categories of fracturing and explosivity of pyroxenites depending on the average diameter of the individual and the specific consumption of Explosives

\begin{tabular}{|c|c|c|c|c|c|}
\hline \multicolumn{2}{|c|}{ Category } & \multicolumn{2}{|c|}{$\begin{array}{c}\text { Average diameter of } \\
\text { the individual, } m\end{array}$} & \multirow{2}{*}{$\begin{array}{c}\text { Compressive } \\
\text { strength of rock, } \\
\mathrm{MPa}\end{array}$} & \multirow{2}{*}{$\begin{array}{c}\text { Specific consump- } \\
\text { tion of Explosives, } \\
\mathrm{kg} / \mathrm{m} 3\end{array}$} \\
\hline fractures & Explosivity & $\begin{array}{l}\text { in the } \\
\text { array }\end{array}$ & $\begin{array}{c}\text { in the } \\
\text { mountain } \\
\text { mass }\end{array}$ & & \\
\hline I-II & $\begin{array}{l}\text { easily } \\
\text { exploding }\end{array}$ & $\leq 0,5$ & $0,15-0,20$ & $30-60$ & $0,5-0,7$ \\
\hline III & $\begin{array}{l}\text { average } \\
\text { explosive }\end{array}$ & $\begin{array}{c}0,5- \\
1,0 \\
\end{array}$ & $0,20-0,25$ & $50-100$ & $0,7-1,0$ \\
\hline IV & $\begin{array}{l}\text { hard - to - } \\
\text { explode }\end{array}$ & $\begin{array}{l}1,0- \\
1,5\end{array}$ & $0,25-0,35$ & $90-150$ & $1,0-1,4$ \\
\hline V & $\begin{array}{l}\text { very difficult } \\
\text { to explode }\end{array}$ & $\geq 1,5$ & $\geq 0,35$ & $150-210$ & $1,4-1,8$ \\
\hline
\end{tabular}

In Table 2, a comparison of the rocks measured by outcrops and calculated according to the dependence (2) of the sizes of "natural" separations in the massif is carried out. The magnitude of the devia- 
tions of the calculated dimensions in absolute units varies within 3-5 $\mathrm{cm}$ or in percentage terms $-12-15 \%$. This indicates the sufficient reliability of the proposed fracture assessment methodology [22].

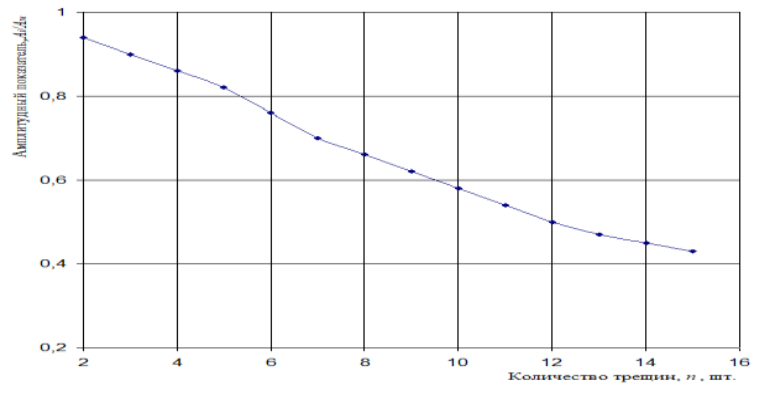

Fig. 2. Dependence of the amplitude index of fracturing $\left(A_{i} / A_{m}\right)$ on the number of cracks $(n)$

Thus, the determination of the fracturing intensity of the rock mass using amplitude indicators should be performed in the following sequence.

1. The absorption coefficient of the energy of the passing wave in the monolith ("natural" separations) is determined. To do this, explosions of charges of the same weight are produced, isolated in an array of natural separations of different lengths with fixation of the amplitudes of voltage waves at different measurement bases.

2. In a section with a known degree of fracturing of the array, measurements are made of the actual amplitudes of elastic waves excited by charges of the same weight. According to these data, the value of the coefficient a is calculated, which characterizes the crack parameters.

3. The average size of natural separations in any other part of the array is calculated from the measured value of the amplitudes Ai using the obtained ratio (2).

So, the proposed fracturing assessment technique has been tested in underground conditions and has shown sufficient reliability in determining the fracturing intensity of a rock mass. The advantage of this technique is that with the help of amplitude indicators, it is possible to determine the average size of the "natural" individual composing the array, which is extremely important to know for calculating the parameters of drilling and blasting operations in fractured rocks. 
As a result of the study of the fracturing of the deposit, it was found that the most disturbed cracks are the ore arrays of sections "1" and "2". The maximum dimensions of the ribs of the structural units in them are approximately the same and equal to $600 \mathrm{~mm}$, however, the nature of the cracks and the material of their filling are different. The site " 1 " of the deposit is characterized by a large crack opening. The ores of site "2" are brittle, the cracks are mostly closed and "healed". The section " 3 " is the least disturbed by cracks, it is characterized by the presence of a large number of quartered rocks. The maximum size of the natural part in it is $1000 \mathrm{~mm}$.

\subsection{Determination of the parameters of destruction of the structural block array on the contour of the mining}

The destruction of the structural block array on the contour of the mining takes place when the stress concentration leads to an excess of the strength of the rock. The parameters of the destruction zone are related to natural factors (the natural stress field, the properties of rocks in the array) and technological (the cross section of the workings, the layout of the holes, the flow rate of explosives and the mode of exploding charges, etc.).

The structure of the rock mass has a great influence on the efficiency of drilling and blasting operations during the excavation and during the treatment of ore. The strength of a rock in a monolithic sample and in an array broken by cracks may differ by orders of magnitude.

When the hole is located in close proximity to the plane weakening the crack array, most of the explosion energy is dissipated in the pore space of the latter. This significantly reduces the effectiveness of the explosion, increases the output of the oversized, and also leads to the destruction of the contour zone if the crack extends beyond the production contour.

All of the above points to the importance of knowing the structure of the massif in the vicinity of mining workings when drafting BVR projects. The degree of influence of cracks in some cases is taken into account by lowering the structural strength of the rock, and in others - through adhesion and the angle of internal friction, which are indicators of mechanical coupling between individual blocks of rock in a state of extreme equilibrium. Naturally, depending on the ac- 
cepted estimated strength characteristics, the structure of the proposed calculation formulas also changes and, in many cases, they differ significantly from each other. Therefore, it would be extremely imprudent to take as a basis any recommendation without preliminary verification for a specific deposit. Taking this into account, we studied the issues of determining the degree of influence of cracks on the strength of rocks in the roof of the mine in relation to the Yubileynoye deposit.

Below is a description of studies of the effect of cracks oriented parallel and normal to the direction of action.

Samples with a normal layering arrangement to the direction of the destructive load also consisted of three layers. The nature of the destruction of the extreme layers is the same as that of monolithic samples and the shear surfaces extend to the boundaries of the middle layer. At the boundary with the middle layer, the destruction occurs with a shift along the surface of the cracks. After that, the middle layer begins to collapse with the formation of shear surfaces similar to Luders sliding surfaces under shear deformations in brittle metals [6].

The effect of horizontal layering on the compressive strength of samples is less pronounced. For example, the strength of tested samples with one horizontal crack almost exactly coincides with the strength of a monolithic sample. And the strength of the sample with two horizontal cracks turned out to be less than the strength of the monolithic sample by only $3 \%$.

In the dissertation of E.S. Radenko [7], a dependence is given for determining the fracturing coefficient of $C_{t}$, taking into account the weakening of a massive ore column with a height of hc due to the presence of $V_{b l}$ volume separations formed by the intersection of three main systems of cracks in it

$$
K_{m}=\left(\frac{h_{u}}{\sqrt[3]{V_{\text {бл }}}}\right)^{-0,6},
$$

The presence of weak interlayers in the body of the whole is recommended to be taken into account by the coefficient of heterogeneity $K_{n}$, determined by the dependence 


$$
K_{H}=1-\sqrt{\frac{h_{c l}}{h_{0}}} \cdot(1-\eta),
$$

where $h_{c л}$ - the power of the weak interlayer in the body of the whole, m;

$h_{0}$ - total height of the whole, m;

$\eta$ - the ratio of the cubic strengths of the interlayer rock and ore.

In the monograph by V.I. Borsch-Companietz [8], the dependence of the influence of the fracture intensity $(H / h)$ on the value of the structural attenuation coefficient (the ratio of rock adhesion in the $K_{m}$ array to adhesion in the $K_{k}$ piece) is presented. This curve is approximated by an analytical dependence of the form

$$
K_{M}=K_{\kappa}\left(\frac{H}{h}\right)^{-0,6},
$$

where $H$ - the characteristic size of the considered area of the array, m;

$h$ - the average size of individual rocks in this zone, $\mathrm{m}$.

For surfaces that do not coincide with the attenuation surfaces, according to the results of field tests of samples with normally secant layering by G.L. Fisenko [9], the dependence between the adhesion of rock in a piece and an array was established

$$
K_{\mu}=\frac{K_{\kappa}}{1+a \cdot \ln \frac{L}{l}},
$$

where $K_{\kappa}$ - coupling in a piece of rock, $\mathrm{Pa}$;

$a$ - coefficient depending on the strength of the rock in the piece and the nature of fracturing;

$L$ - the length of the considered section of the array, m;

$l$ - the size of the rock block in the array, $\mathrm{m}$.

If we use an expression that is defined by the Mora stress circle,

$$
K=\frac{\sigma_{\kappa}}{2} \operatorname{tg}\left(\frac{\pi}{4}-\frac{\rho}{2}\right),
$$

then you can imagine this dependence in the form of

$$
K_{\mu}=\frac{\sigma_{\kappa}}{2} K \operatorname{ctg} \theta
$$


For an array weakened by slanting cracks, the following relation is given

$$
K_{\mu}=K^{\prime}+\frac{K_{\kappa}-K^{\prime}}{1+a \cdot \ln \left(\frac{L}{l}\right)}
$$

where $K^{\prime}$ - coupling between individual blocks in the array, Pa;

$L$ - the length of the considered section of the array, m;

$l$ - the size of the rock block in the array, $\mathrm{m}$.

Considering the features of the physico-mechanical properties and structure of the ores of the Talnakh deposit (Russia), D.M. Bronnikov, N.F. Zamesov and G.I. Bogdanov [21] note that in genetically and mineralogically homogeneous ores, strength is closely related to the size of the natural separation. Thus, with the size of the natural separation in the range of 200-300 mm, the strength limit of the ore for uniaxial compression is in the range of $80-160 \mathrm{MPa}$ (average $110 \mathrm{MPa}$ ), with a decrease in the size of the separations to $100-200 \mathrm{~mm}$, the observed strength of the ore decreased to 50-130 MPa (average $80 \mathrm{MPa}$ ) and, finally, in ore with a size of 50-100 $\mathrm{mm}$ separations, the strength of the ore reached the level of 15-65 MPa (average $35 \mathrm{MPa}$ ).

I.V. Baklashov and K.V. Ruppeneit [10] proposed a dependence for determining the stress concentration on the production circuit due to its technogenic roughness

$$
K_{\sigma}=1+\frac{h_{g n}\left(n_{s n}-1\right)}{2 R} / 1-\frac{h_{g n}\left(n_{s n}-1\right)}{2 R},
$$

where $h_{\mathrm{Bп}}$ - depth of depressions on the contour of the mining, $\mathrm{m}$;

$R$ - the radius of the zero contour dividing the areas of depressions and protrusions equally, $\mathrm{m}$;

$n_{\text {вп }}$ - the number of depressions on the zero production circuit, pcs.

Measurements made by VNMI employees at the mines of Gornaya Shoria (Russia) showed that the stress concentration in the roof depressions reaches $5.5 y H$, which is why even in strong rocks dynamic forms of mountain pressure are observed. Calculations show that the use of smooth blasting reduces stresses on the contour of production about 1.7-1.8 times.

Y.M. Kartashov, V.B. Matveev, G.V. Mikheev and A.B. Fadeev [11], considering the uniaxial compression of the layered structure along the strata, came to the conclusion that the resistance of the 
structure is determined by the longitudinal stability of the layers when the ratio $h / b>16$, and at a lower relationship strength does not depend on $h / b$ and equal to the strength of the monolith.

However, in fact, the stability of the layers depends on this ratio even at $h / b<16$, due to the inevitable non-parallelism of the layers, uneven load distribution between the layers, and, most importantly, due to the eccentricity of the load application on each layer.

If there is a connectedness between the layers of the structure characterized by tensile strength $\sigma \mathrm{p}$, then a compression stress equal to

$$
\sigma_{c} \geq \sigma \geq \sigma_{c} \frac{\sigma_{p}^{\prime}}{\sigma_{p}},
$$

where $\sigma_{\mathrm{c}}$ и $\sigma_{\mathrm{p}}$ - compressive and tensile strength of the rock, $\mathrm{MPa}$.

Consider the resistance to uniaxial compression of a structural medium such as brickwork. If there is no adhesion along the cracks, then a load 2 times less will be required to break the sample along the vertical plane than for the formation of such a gap in a monolithic sample, since there is already a gap in the form of initial cracks at half the distance [11].

After the formation of a series of longitudinal breaks, the frequency of which will be determined by the size of the structural block b, the columns may immediately lose stability and collapse if their height significantly exceeds the thickness. If the columns are wide enough, that is, with a small $\mathrm{b} / \mathrm{h}$ ratio, they can resist stress growth up to the strength level of a monolithic sample.

D.M. Kim conducted a series of experiments in the laboratory to assess the strength of prefabricated prisms of a similar structure. He found that for the compressive strength of the material of cubesblocks of $8 \mathrm{MPa}$, as $h / b$ increases, the strength of the prefabricated structure decreases to the level of $40 \%$ of the strength of the monolith, and after reaching $b / h=14$ or more remains constant [12].

Analysis of the stability of fractured structures allows us to establish the reason for the dependence of strength on the ratio of the size of the loaded zone and the elementary structural block - one of the forms of manifestation of the large-scale effect.

The amount of compressive strength is significantly affected by the orientation of the attenuation surface in the array with respect to 
the direction of action of the compressive load. The greatest decrease in strength occurs when the secant cracks are located at an angle $\alpha=\frac{\pi}{2}-\frac{\rho}{2}$ in the direction of the compressive load. The compression resistance of the structure along the layers, taking into account the orientation of the slanting cracks, can be determined analytically for each layer separately according to the following formula

$$
\sigma_{M}=\frac{K_{M} \cos \rho_{M}}{\cos \rho \sin \left(\beta-\rho^{1}\right)}
$$

where $K_{M}, \rho_{M}$ - accordingly, the adhesion and the angle of internal friction in the monolithic rock, $\mathrm{Pa}$ and degrees;

$\beta$ - the angle between the normal to the layering and the crack trace;

$\rho^{\prime}$ - the angle of friction on the crack surface, degrees;

At the angle $\beta \leq \rho_{M}$, and also close to $\rho_{M}$, the compressive resistance of the rock in the massif becomes equal to the compressive strength of high monolithic samples.

The natural massif is always divided into cracks, which cause a sharp decrease in the connections between natural separations. Since a single sample cannot characterize the state of the rock mass as a whole, it is desirable to determine the strength of rocks in natural conditions, directly in the places of their occurrence, for an adequate assessment of the strength of the array.

The main strength characteristics of a fractured rock mass are: compression resistance, adhesion and the angle of internal friction.

The magnitude of the internal friction angle $p$ depends on the roughness of the shear surfaces of the rock and is usually determined by the granulometric composition of the rock composing individuals.

The larger the size of the separations and the smaller the cementing substance per unit volume, the more pronounced the roughness of the sliding surfaces, hence the higher the coefficient of internal friction $\operatorname{tg} \rho$.

In the monograph [11], the authors give the following analytical expression for determining the resistance limit for a layered fractured medium 


$$
\sigma_{1}=\min \left\{\begin{array}{c}
2 C t g\left(\frac{\pi}{4}+\frac{\varphi}{2}\right)+\sigma_{3} \operatorname{tg}^{2}\left(\frac{\pi}{4}+\frac{\varphi}{2}\right) ; \\
\frac{C^{\prime} \cos \varphi^{\prime}+\sigma_{3} \cdot \sin \alpha \cdot \cos \left(\alpha-\varphi^{\prime}\right)}{\cos \alpha \cdot \sin \left(\alpha-\varphi^{\prime}\right)},
\end{array}\right.
$$

where $C$ и $\varphi$ - coupling and internal friction angle for a monolithic rock sample, $\mathrm{Pa}$ and degrees;

$C^{\prime}$ и $\varphi^{\prime}$ - coupling and the angle of internal friction on the contacts of layering, $\mathrm{Pa}$ and degrees.

If the medium has not one, but several directions of fracturing (structural blockiness), then the previous condition is somewhat modified

$$
\sigma_{1}=\min \left\{\begin{array}{c}
2 C \cdot \operatorname{tg}\left(\frac{\pi}{4}+\frac{\varphi}{2}\right)+\sigma_{3} \operatorname{tg}^{2}\left(\frac{\pi}{4}+\frac{\varphi}{2}\right) ; \\
\frac{C_{i}^{\prime} \cos \varphi_{i}^{\prime}+\sigma_{3} \cdot \sin \alpha_{i} \cdot \cos \left(\alpha_{i}-\varphi_{i}^{\prime}\right)}{\cos \alpha_{i} \cdot \sin \left(\alpha_{i}-\varphi_{i}^{\prime}\right)}, i=1,2,3
\end{array}\right.
$$

I.A. Turchaninov et al. the authors in the monograph [14] note that the influence of dynamic loads from blasting operations in a wide range of mining and geological conditions is almost the same and leads to additional weakening of rocks around the mine at a distance of $20-40 \mathrm{~cm}$ from the contour. Due to the block structure of rock arrays, their resistance to tensile stresses is very small, so that in engineering calculations, the tensile strength of rocks in the array can be assumed to be zero. In such cases, the area of rock destruction around the mine will coincide with the area of tangential stresses. At the same time, it is convenient to characterize the strength of rocks by the values of adhesion $\tau_{0}$ and the angle of internal friction $\varphi$. The form of destruction in this case is the relative displacement (shift) of individual parts of the rock.

The area of tensile stresses in the roof of the workings with a rectangular cross-sectional shape is limited by a vaulted curve.

When only compressive stresses are applied in the massif around the production, rock destruction may occur by crushing structural blocks at high stresses or by chipping along the surface of natural cracks, that is, destruction only in the area of contacts between structural blocks. 
According to the theory of limiting equilibrium, the condition of non-destruction over the shear surface is determined by the inequality, $\mathrm{Pa}$

$$
\tau_{x, y}<\tau_{0}+\sigma_{n} \cdot \operatorname{tg} \varphi
$$

where $\tau_{x, y}$ - effective tangential stress, Pa;

$\sigma_{n}$ - the normal component of the compressive stress acting on the slip pad, Pa.

In turn, the normal and tangential components on the sliding surface are determined by the dependencies

$$
\left.\begin{array}{rl}
\tau_{x y} & =\frac{\sigma_{y}}{2} \sin 2 \alpha ; \\
\sigma_{n} & =\sigma_{y} \cdot \cos ^{2} \alpha+\sigma_{x} \sin ^{2} \alpha,
\end{array}\right\}
$$

where $\sigma_{y}$. и $\sigma_{x}$. - accordingly, the maximum and minimum main voltages, $\mathrm{Pa}$;

$\alpha$ - the angle of inclination of the sliding surface to the line of action of the minimum main voltage $\sigma_{x}$.

Taking into account the dependencies (16), the limit equilibrium condition takes the following form

$$
\frac{\sigma_{y}-\sigma_{x}}{2} \cdot \sin 2 \alpha<\tau_{0}+\left(\sigma_{y} \cdot \cos ^{2} \alpha+\sigma_{x} \cdot \sin ^{2} \alpha\right) \cdot \operatorname{tg} \varphi
$$

or after converting the expression in parentheses

$$
\frac{\sigma_{y}-\sigma_{x}}{2} \cdot \cos 2 \alpha(\operatorname{tg} 2 \alpha-\operatorname{tg} \varphi)<\tau_{0}+\frac{\sigma_{y}+\sigma_{x}}{2} \cdot \operatorname{tg} \varphi \text {. }
$$

The collapse of the structural separation on the contour of the mining is possible only in the case of simultaneous implementation of the cleavage on the surfaces of the I, II, III crack systems, while on the upper horizontal face of the separation, the block must be detached from the overlying part of the array. Of course, this is the case when the size of the individual is significantly smaller than the span of the mining.

In [14] it is noted that for the condition of non-destruction of sections of the rock mass weakened by differently oriented cracks, the provision of three inequalities is necessary 


$$
\left.\begin{array}{l}
\frac{\sigma_{y}-\sigma_{x}}{2} \cdot \cos 2 \alpha\left(\operatorname{tg} 2 \alpha-\operatorname{tg} \varphi_{m p}\right)<\tau_{m p}+\frac{\sigma_{y}+\sigma_{x}}{2} \cdot \operatorname{tg} \varphi_{m p} \\
\frac{\sigma_{z}-\sigma_{x}}{2} \cdot \cos 2 \alpha\left(\operatorname{tg} 2 \alpha-\operatorname{tg} \varphi_{m p}\right)<\tau_{m p}+\frac{\sigma_{z}+\sigma_{x}}{2} \cdot \operatorname{tg} \varphi_{m p} \\
\frac{\sigma_{y}-\sigma_{z}}{2} \cdot \cos 2 \alpha\left(\operatorname{tg} 2 \alpha-\operatorname{tg} \varphi_{m p}\right)<\tau_{m p}+\frac{\sigma_{y}+\sigma_{z}}{2} \cdot \operatorname{tg} \varphi_{m p}
\end{array}\right\}
$$

where $\tau_{m p}$ и $\varphi_{m p}$ - adhesion and the angle of internal friction on the surfaces of natural cracks, $\mathrm{Pa}$ and degrees.

The conditions for the implementation of chipping on the surfaces of natural cracks allow us to estimate the size of the zone of possible falls from the walls and roof of the workings.

I.A. Turchaninov offers a dependence for determining the stability of structural blocks to fall into the workings

$$
\frac{\gamma}{2 f_{\mathrm{o}} P}>\frac{1}{a}+\frac{1}{b},
$$

where $a$ and $b$ - transverse dimensions (in plan) structural blocks, m;

$P$ - strut of structural blocks, MPa;

$f_{0}$ - coefficient of friction on the surfaces of cracks of separations;

$\gamma$ - volume weight of the rock, $\mathrm{MN} / \mathrm{m} 3$.

V.M. Mostkov [16] recommends determining the depth of the zone of disturbed rocks around the mine by the formula, $\mathrm{M}$

$$
h_{H}=K \cdot{ }_{0},
$$

where $B_{0}$ - production span, m;

$K$ - a dimensionless coefficient, depending on the strength of the rocks, for $f=10$ and higher, $K=0,05-1$.

The angle of internal friction and adhesion of the rock is established by testing rock samples for a cut and drawing up a strength passport. Research by Y.M. Kartashev et al. the authors found that the values of the angle of internal friction determined on the surface between the banks of the crack and in a monolithic piece are values of the same order. If the crack surfaces are sanded or filled with abrasion products, the value of the internal friction angle is reduced by $5-10 \%$ [11].

The calculation of the parameters of drilling and blasting operations during the sinking of underground workings requires taking into account all mining-geological and mining-technical characteristics of the rock mass. In addition to the physical and mechanical 
properties and fracturing, it is necessary to take into account the directions of the main stresses in the array. It is possible to get an idea of the main stresses $\left(\sigma_{1}, \sigma_{2}\right)$ in the rock mass using the deformation ellipsoid [15].

The deformation ellipse can be constructed according to the data of the study of crack systems in the rock mass. In this case, the ellipse fits into the structural separateness formed by systems of cracks. In another way, the deformation ellipse can be obtained using the method of measuring residual stresses by drilling holes in a loaded array. According to this method, a round hole is drilled in the rock, the shape of which is deformed into ellipses under the influence of uneven stresses, as shown in Fig. 3.

The deformation ellipse makes it possible to determine the effective normal stress using Hooke's law

$$
\sigma=E \cdot \Delta d / d
$$

where $\Delta d / d$ - relative deformation;

$\Delta d=2 a-d$ ) - the magnitude of the absolute deformation of the hole;

$a$ - the large semi-axis of the ellipse formed as a result of the manifestation of residual stresses;

$d$ - bore diameter;

$E$ - the modulus of elasticity of the rock.

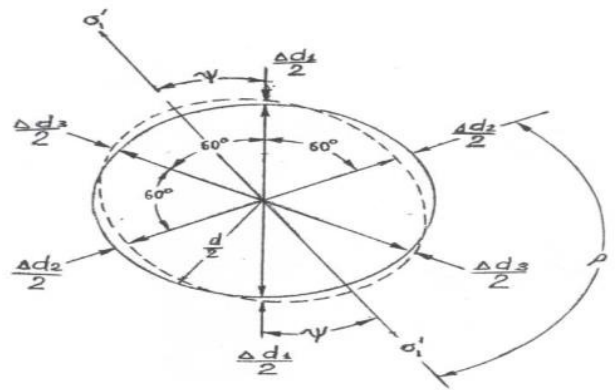

Fig. 3. Diagram of determining the direction and magnitude of the main compression stresses in the array by measuring the deformation of the cross-section of the borehole (hole)

The ellipse of the deformation obtained by distorting the hole of the initially round shape can serve as a "stress characteristic" of the rock mass. An ellipsoid (in the plane of an ellipse) is an image of the anisotropy of a triaxial space and finds application in many areas of 
mechanics, in particular, the construction of an ellipsoid of deformation of rocks is carried out by systems of cracks.

If the natural separateness of a rocky-fractured rock mass has a symmetrical shape (rectangle, rhombus), then the construction of cracks according to such systems is simplified, since the axes of these figures serve as ellipse diameters. In general, the construction of a deformation ellipse on the plane is reduced to its insertion into a parallelogram. The axes of this ellipse coincide in the direction of the main stresses.

In practice, a diameter measuring device is inserted into a round hole (borehole or borehole). To calculate the main stresses $\sigma_{1}, \sigma_{2}$ and the direction $\beta$ of the main voltage, the dependences should be used

$$
\begin{gathered}
\sigma_{1}\left(\sigma_{2}\right)=\frac{E}{6 d}\left[\left(\Delta d_{1}+\Delta d_{2}+\Delta d_{3}\right) \pm\right. \\
\left. \pm \sqrt{\frac{\left(\Delta d_{2}-\Delta d_{1}\right)^{2}+\left(\Delta d_{1}-\Delta d_{3}\right)^{2}+\left(\Delta d_{3}-\Delta d_{2}\right)^{2}}{2}}\right] \\
\beta=\frac{1}{2} \operatorname{arctg} \frac{3\left(\Delta d_{1}-\Delta d_{3}\right)}{2 \Delta d_{2}-\Delta d_{1}-\Delta d_{3}}
\end{gathered}
$$

If a parallelogram is described around the deformation ellipse, then we get an oriented model of natural separation, the sides of which are the dominant systems of cracks. The axes of the deformation ellipse indicate the directions of maximum and minimum deformations in the rock mass. In this case, the angle $\psi$ - deviation of the sides of the parallelogram from the diameters of the ellipse can vary from 0 to $45^{\circ}-p / 2$ and is determined by the dependence

$$
\cos \psi=b_{1} / b \cos 45^{\circ}(\cos \rho / 2-\sin \rho / 2),
$$

where $b_{1}$ - the short side of the parallelogram;

$b$ - the minor semimajor axis of the ellipse.

In our case, the reverse side is solved, but the angle $\psi$ will have the same meaning.

From all of the above, it follows that the holes should be drilled, if possible at equal distances from the crack systems, but in no case on the cracks themselves.

The charges should be positioned normal to the crack systems. To do this, it is necessary to determine the orientation of the dominant 
systems of cracks in the face by surveying and processing its results by known methods or using the residual stress method to construct a parallelogram of structural separation.

When calculating explosive charges, in addition to the structural attenuation coefficient in the direction of the main stress, the coefficient $\sigma_{2} / \sigma_{1}$ can be used, while the destructive load on the rock increases, since the main stress in the rock mass is added to the explosion force.

\subsection{Dependence of the quality of the contouring of the mine workings on the design of the explosive charge}

Recently, when developing mineral deposits, special attention has been paid to efficient resource-saving technologies for ore extraction. One of the promising ways to ensure the efficiency of ore deposit development technology is to increase the stability of mine workings and reduce the level of dilution of the extracted ore, which are achieved by accurately reproducing the design position of the contour of preparatory and rifled workings in the process of their implementation and reducing the seizure of waste rock during treatment excavation.

Deviation from the design contour, accompanied in practice by an increase or decrease in the section of the mining, leads to a larger volume of rock for each meter of penetration, the so-called rock sorting, or to unproductive work on the subsequent reduction of the contour of the workings to the position required by the project with a decrease in the section of the workings with poor-quality rock mass, accompanied by a "shortage of rock".

The reason for the mismatch of the excavation contour with the design position is a number of factors, among which the most significant are:

the impossibility of locating the holes directly on the surface of the design contour of the development;

a limited number of contouring holes in the faces of preparatory and cleaning workings;

sawtooth shape of rock mass separation, both in the cross section of the contour and along the length of the excavation;

the structural destruction of the rock due to the dynamic impact of the explosion of charges of considerable power; 
collapses in the roof of workings caused by the manifestation of increased mountain pressure.

Ensuring high-quality delineation of the design position of the mining is one of the serious tasks of drilling and blasting operations during the conduct of the cleaning excavation. Failure to comply with this condition leads, in some cases, to overburden of rock in excess of the design section, entailing dilution of the extracted ore, in others - to a shortage of the beaten ore, causing its loss in the bowels. Well-known methods of reducing the busting or shortage of the design contour surface (the use of small diameter boreholes, switching to another type of Explosive, etc.) do not give significant results, since the optimal ratio of the parameters of the borehole with the properties of the rock mass is not taken into account.

To obtain rational parameters of contour detonation, experimental explosions were carried out in laboratory conditions, taking into account the characteristics of the Yubileynoye deposit and different charge designs.

It is known that carrying out experimental work in production conditions causes certain difficulties, since the sinking of workings and the removal of ore in the treatment faces are carried out according to projects and passports approved and agreed with the mining inspection. Changing the parameters of blasting operations in the interests of research violates production plans and programs, requires coordination with supervisory authorities, etc.

Laboratory studies were carried out on models made of equivalent materials in compliance with the similarity criteria. A mixture of rosin, sealing wax and lead concentrate was used as an equivalent material, Such a composition ensured the uniformity of the structure of the model, made it possible to select the necessary strength properties of the equivalent material.

A rattlesnake chloride mixture was used as an explosive. The shell of the cartridges was made in the form of tubes glued together from paper tracing paper. The initiation of charges was carried out using a constantan wire, which was inserted directly into the explosive cartridge. The connection of the electrical circuit for detonating the charges ensured their sequential detonation with a deceleration of $0.5-1 \mathrm{c}$.

Laboratory studies of explosive rebounding were carried out to study the impact on the quality of contouring of mining such technological factors as 
the distance between contouring holes, the line of least resistance, the value of the specific flow rate of explosives, the design of the hole charge. The obtained results of laboratory studies are shown in Table 3.

The data obtained in the experiment are given in terms of nature in terms of the scale factor $M=1: 30$. In all series of the experiment, the length of the holes was assumed to be $1.4 \mathrm{~m}$, the diameter of the hole was $45 \mathrm{~mm}$.

As can be seen from the table, with a solid charge design, a change in the specific consumption of explosives for breaking from 2.5 to $2.9 \mathrm{~kg} / \mathrm{m}^{3}$, that is, by $16 \%$, led to an increase in the sorting of rock behind the production contour by $33 \%$, at the same time, the distance of the discarded rock mass increased by $12 \%$.

Table 3

Experimental data on the evaluation of the search of the sculptural array and the amount of waste of the recaptured rock mass from the parameters of drilling and blasting operations

\begin{tabular}{|c|c|c|c|c|c|c|}
\hline $\begin{array}{l}\text { Working } \\
\text { section, } \\
\mathrm{m}^{2}\end{array}$ & Charge design & $\begin{array}{l}\text { Distance } \\
\text { between the } \\
\text { holes, } m\end{array}$ & $\begin{array}{c}\text { Number } \\
\text { of holes, } \\
\text { units. }\end{array}$ & $\begin{array}{l}\text { The size } \\
\text { of the } \\
\text { bust, } \mathrm{m}^{3}\end{array}$ & $\begin{array}{c}\text { Specific } \\
\text { consumption } \\
\text { of Explo- } \\
\text { sives, } \\
\mathrm{kg} / \mathrm{m}^{3} \\
\end{array}$ & $\begin{array}{l}\text { Discarded rock } \\
\text { mass, } \mathrm{m}\end{array}$ \\
\hline 14,0 & Solid & 0,49 & 8 & 0,300 & 2,50 & 8,90 \\
\hline 14,0 & $\ll$ & 0,52 & 8 & 0,315 & 2,60 & 9,00 \\
\hline 14,0 & $\lll$ & 0,54 & 8 & 0,325 & 2,65 & 9,10 \\
\hline 14,0 & $\ll$ & 0,56 & 8 & 0,340 & 2,70 & 9,20 \\
\hline 14,0 & $\ll$ & 0,57 & 8 & 0,349 & 2,75 & 9,35 \\
\hline 14,0 & $\ll$ & 0,58 & 8 & 0,359 & 2,80 & 9,50 \\
\hline 14,0 & $\ll$ & 0,60 & 8 & 0,400 & 2,90 & 10,00 \\
\hline 16,0 & Dispersed & 0,45 & 9 & 0,023 & 1,30 & 4,85 \\
\hline 16,0 & $\ll$ & 0,48 & 9 & 0,028 & 1,40 & 4,88 \\
\hline 16,0 & $\ll$ & 0,53 & 9 & 0,033 & 1,45 & 4,90 \\
\hline 16,0 & $\ll$ & 0,55 & 9 & 0,036 & 1,55 & 4,92 \\
\hline 16,0 & $\ll$ & 0,56 & 9 & 0,040 & 1,65 & 4,95 \\
\hline 16,0 & $\ll$ & 0,58 & 9 & 0,042 & 1,80 & 4,98 \\
\hline 16,0 & $\ll$ & 0,60 & 9 & 0,046 & 1,87 & 5,00 \\
\hline
\end{tabular}

With a dispersed charge design, an increase in the specific consumption of explosives for breaking from 1.3 to $1.87 \mathrm{~kg} / \mathrm{m} 3$, or by $43.8 \%$, led to a 2 -fold increase in the structural sorting of the rock, and the rejection of the rock mass beaten off by the explosion increased by only $3 \%$. However, it should be noted that by absolute value, the level of rock sorting with dispersed charges turned out to be an order of magnitude less than with solid charges. A slight increase in the waste of rock with an increase in the specific consumption of explosives for breaking with dispersed charges indicates that 
the energy of the explosion in this case is more spent on crushing the rock than with a solid charge design.

The experimental data were processed by methods of mathematical statistics, the second-order equation was used as the functional dependence of the nonlinear regression

$$
y=a+b x+x^{2}
$$

For a solid charge, the amount of rock sampling $\Delta h$ is approximated by the following expression, $\mathrm{M}^{3}$

$$
\Delta h=0,329 q_{B 8}^{2}-1,53415 q_{B 8}+2,07816,
$$

where the correlation coefficient between the parameters is $R=0,98$.

For dispersed charges, the regression equation of the dependence of the rock sorting on the specific consumption of Explosives takes the following form, $\mathrm{m}^{3}$

$$
\Delta h=-0,04247 q_{B 8}{ }^{2}+0,17314 q_{B 8}-0,13022,
$$

where the correlation coefficient between the parameters is $R=0,96$.

The value of the distance of the rock ejection by explosion, depending on the specific consumption of the Explosive substance during solid charges, is approximated by the following nonlinear equation of the second order, $\mathrm{M}$

$$
l_{\text {om } \delta}=6,19047 q_{B 8}{ }^{2}-30,73807 q_{B \varepsilon}+47,06425,
$$

where the correlation coefficient between the parameters was $R=0,96$.

The equation of the relationship between the value of the discarded rock mass and the specific consumption of Explosives with a dispersed charge design is expressed by the following dependence, $\mathrm{M}$

$$
l_{\text {om } \sigma}=-0,11514 q_{B \beta}{ }^{2}+0,61735 q_{B \beta}+4,24357,
$$

where the tightness of the relationship between the parameters is characterized by a correlation coefficient $R=0,98$.

The correlation coefficient between the dependent variables was calculated by Bravais-Pearson [68] using the following relation

$$
r_{x, y}=\sum_{i=1}^{n}\left(x_{i}-\bar{x}\right)\left(y_{i}-\bar{y}\right) / \sqrt{\sum_{i=1}^{n}\left(x_{i}-\bar{x}\right)\left(y_{i}-\bar{y}\right)},
$$

Graphs of the dependences of the change in the size of the bust (26) and (27) and the distance of the discarded rock mass from the 
bottom of the mine, depending on the specific consumption of explosives (28) and (29) are shown in Fig. 4 and 5.
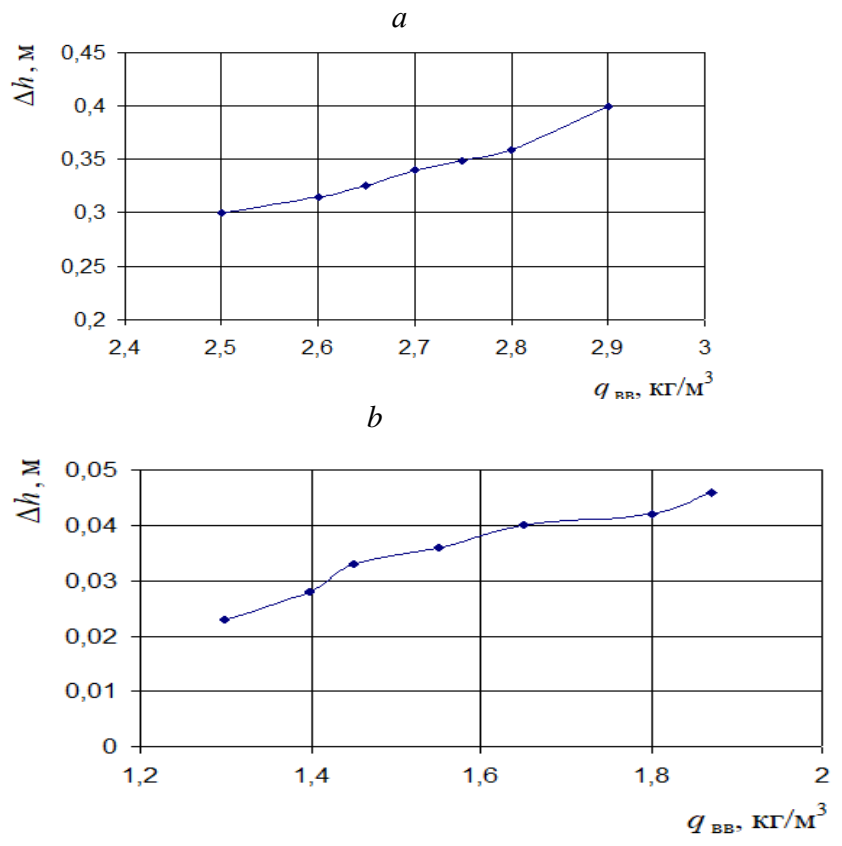

Fig. 4. Dependence of the change in the amount of rock sampling $(\Delta h)$ in the roof of the mine on the specific consumption of Explosive $(q v b): a$ - solid charge; $b$ - dispersed charge design

$a$

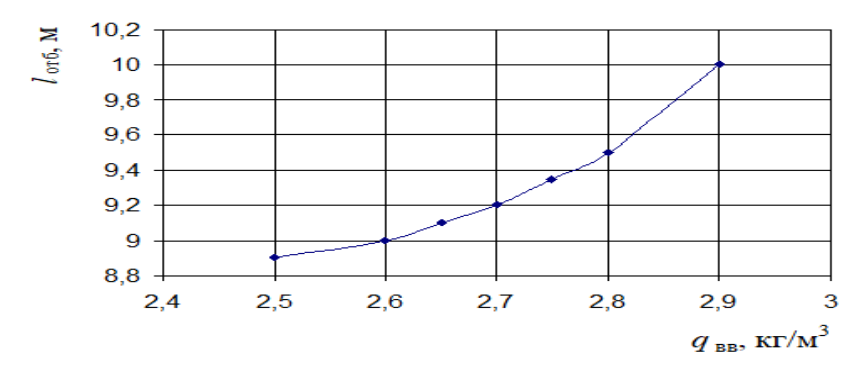




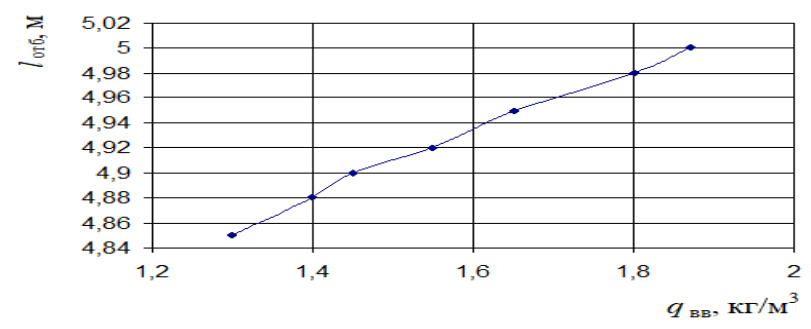

Fig. 5. The dependence of the value of the discarded rock masson the specific consumption of Explosives with different designs of the core charge: $a$ - solid charge; $b$ - dispersed charge design

\subsection{Investigation of the dependence of the utilization factor of the hole on the grid of the location of charges and the specific consumption of Explosives}

In the labor intensity of the extraction of strong ores, the specific weight of drilling and blasting operations is $26-37 \%$, including drilling operations $20-29 \%$. The share of drilling and blasting operations in the cost of ore in the general technological cycle of processes exceeds $60 \%$ [17].

Such a high importance of drilling operations in the technology of ore extraction determines the importance of maximizing such technical and economic indicators as the yield of ore from $1 \mathrm{~m}$ of the well and the utilization factor of the length of the hole.

When carrying out mining operations by drilling and blasting in underground mines, the losses of boreholes in the so-called "glasses" often exceed $20 \%$. At some mines, the utilization rate of boreholes is 0.5-0.6, which not only entails economic losses, but also increases the danger to miners, since with an increase in the depth of the abandoned glasses, the probability of accidents from the detonation of incompletely detonated charges sharply increases.

I.M. Murzikov et al. the authors [13] propose to provide an increase in efficiency through the use of powerful Explosives such as detonites, an increase in the specific consumption of Explosives from $0.6-0.7$ to $1-1.2 \mathrm{~kg} / \mathrm{m}^{3}$ and the number of holes in the kit. This recommendation is valid, except for the obviously underestimated values of the specific consumption of Explosives, most likely associated with the erroneous use of the given dimension. Table 4 shows the results of a study of the dependence of the utilization factor of the 
length of the hole on the number of holes in the set during mining operations at the Gaysky mine (Russia).

Table 4

Dependence of the utilization factor of the hole length on the number of holes

\begin{tabular}{c|c|c|c|c|c}
\hline \multicolumn{3}{c|}{ Basic technology } & \multicolumn{3}{c}{ Experimental technology } \\
\hline $\begin{array}{c}\text { Number of } \\
\text { holes }\end{array}$ & $\begin{array}{c}\text { the utili- } \\
\text { zation } \\
\text { factor of } \\
\text { the } \\
\text { length of } \\
\text { the hole }\end{array}$ & $\begin{array}{c}\text { Hole } \\
\text { losses, } \mathrm{m}\end{array}$ & $\begin{array}{c}\text { Number } \\
\text { of holes } \\
\text { zation } \\
\text { factor of } \\
\text { the } \\
\text { length of } \\
\text { the hole }\end{array}$ & $\begin{array}{c}\text { Hole } \\
\text { losses, } \mathrm{m}\end{array}$ \\
\hline 30 & 0,50 & 30 & 38 & 0,80 & 6,2 \\
30 & 0,50 & 31 & 40 & 0,99 & 9,8 \\
32 & 0,51 & 30 & 40 & 0,91 & 4,0 \\
32 & 0,52 & 30,7 & 42 & 0,96 & 6,6 \\
32 & 0,60 & 25,6 & 44 & 0,90 & 3,8 \\
35 & 0,55 & 31,5 & 44 & 0,86 & 2,6 \\
38 & 0,60 & 30,4 & 44 & 0,94 & 2,3 \\
38 & 0,60 & 30,4 & 44 & 0,90 & 6,9 \\
38 & 0,70 & 21,6 & 49 & 0,95 & 3,1 \\
\hline
\end{tabular}

* Note - the losses of boreholes in $\mathrm{m}$ are given for one set

From the above data, it can be seen that in the conditions of the Gaisky mine (the cross section of the output is $12-14 \mathrm{~m}^{2}$, the depth of the holes is $2 \mathrm{~m}$, the diameter of the holes is $42 \mathrm{~mm}$, the ore strength is 14-16), the optimal number of holes in the set is 40 , since a further increase in the drilling density of the holes is not accompanied by a corresponding increase in the utilization factor of the length of the hole.

A particularly noteworthy fact that requires stopping at it is that at the same mine, when working in quartz-ceritic rocks and tuffs with a strength of 6-15 on the M.M. Protodiakonov scale, the utilization factor of the hole length is $0.9-1$, and in the ore zone represented by copper pyrite, as well as in a hardening bookmark with a compressive strength of 3.5-5 $\mathrm{MPa}$, the kish decreases to 0.5-0.7.

To study the regularities of changes in the utilization coefficient of the length of the hole from the grid of the location of charges and the specific consumption of Explosives for breaking rock mass in laboratory conditions, a corresponding experiment was conducted. In the first series of experiments, layers were broken off on a model made of equivalent material with simultaneous changes in the lines of least resistance and the distance between the holes, as well as the 
specific consumption of Explosives. In the experiments, a uniform grid of holes $a=W$ was used. Modeling of the structural blockiness of the array was carried out by laying foil strips into the body of the model, creating an imitation of natural separateness with a size of $25 \times 25 \times 50 \mathrm{~cm}$. In the first series of experiments, the layer was broken off by rows of holes orthogonal to the leading crack system. The results of experimental explosions are shown in Table 5.

Table 5

Change in the utilization factor of the hole and the discarded rock mass from the distance between the holes and the specific consumption of Explosives

\begin{tabular}{c|c|c|c|c|c|c}
\hline № & $\begin{array}{c}\text { Diameter } \\
\text { hole, } d, \\
\mathrm{~m}\end{array}$ & $\begin{array}{c}\text { Hole } \\
\text { depth, } \\
h, \mathrm{~m}\end{array}$ & $\begin{array}{c}\text { Distance } \\
\text { between } \\
\text { holes, } a, \\
\mathrm{~m}\end{array}$ & $\begin{array}{c}\text { Specific } \\
\text { consumption } \\
\text { of Explo- } \\
\text { sives, } q, \\
\mathrm{~kg} / \mathrm{m}^{3}\end{array}$ & $\begin{array}{c}\text { Discarded } \\
\text { rock } \\
\text { mass, } L, \\
\mathrm{~m}\end{array}$ & $\begin{array}{c}\text { the utili- } \\
\text { zation } \\
\text { factor of } \\
\text { the length } \\
\text { of the } \\
\text { hole, } \eta\end{array}$ \\
\hline 1 & 0,038 & 1,4 & 0,20 & 2,6 & 12 & 0,78 \\
\hline 2 & 0,038 & 1,4 & 0,20 & 2,5 & 10 & 0,77 \\
\hline 3 & 0,038 & 1,4 & 0,23 & 2,6 & 11 & 0,75 \\
\hline 4 & 0,038 & 1,4 & 0,25 & 2,7 & 12 & 0,75 \\
\hline 5 & 0,038 & 1,4 & 0,25 & 2,8 & 12 & 0,74 \\
\hline 6 & 0,038 & 1,4 & 0,20 & 2,3 & 7 & 0,73 \\
\hline 7 & 0,038 & 1,4 & 0,23 & 2,4 & 8 & 0,75 \\
\hline 8 & 0,038 & 1,4 & 0,25 & 2,1 & 5 & 0,74 \\
\hline 9 & 0,038 & 1,4 & 0,25 & 2,2 & 6 & 0,73 \\
\hline 10 & 0,038 & 1,4 & 0,26 & 2,2 & 6 & 0,72 \\
\hline 11 & 0,038 & 1,4 & 0,30 & 2,3 & 5 & 0,73 \\
\hline
\end{tabular}

As can be seen from the table, reducing the distance between the holes leads to an increase in the utilization rate of the hole. For example, with a decrease in the distance between the holes from 0.26 to $0.20 \mathrm{~m}$, that is, by $30 \%$, the utilization factor of the length of the hole increases from 0.72 to 0.78 , or by $8.3 \%$. At the same time, there is an increase in the distance of the discarded rock mass by almost 2 times.

By processing the experimental data, the following empirical dependences were obtained: the coefficients of the use of boreholes on the distance between the boreholes and the specific consumption of Explosives

$$
\begin{aligned}
& \eta=2,4241 a^{2}-, 5516 \cdot a+0,9745 ; \\
& \eta=-9,2155 q^{2}{ }_{\mathrm{Bв}}+7,4642 \cdot q_{\mathrm{Bв}}+1,7559,
\end{aligned}
$$

where $\eta$ - he coefficient of use of the length of the hole in the explosion; 
$a$ - distance between the holes, $\mathrm{m}$;

$q_{\mathrm{Bв}}-$ the specific consumption of Explosives for breaking rock mass, $\mathrm{kg} / \mathrm{m}^{3}$.

Fig. 6,7 and 8 show graphs of the change in the utilization factor of the length of the hole from the distance between the holes and the specific consumption of Explosives.

In the second series of experiments (Table 6), explosions were carried out with the consumption of Explosives for breaking increased to $3.2 \mathrm{~kg} / \mathrm{m}^{3}$.

Table 6

Change in the coefficient of use of the length of the hole and the waste of rock mass during the explosion of ore layers with oblique stratification

\begin{tabular}{|c|c|c|c|c|c|c|}
\hline № & $\begin{array}{c}\text { Bore } \\
\text { diameter, } \\
d, \mathrm{~mm}\end{array}$ & $\begin{array}{l}\text { The } \\
\text { length of } \\
\text { the } \\
\text { holes, } 1 \text {, } \\
\text { m }\end{array}$ & $\begin{array}{c}\text { Distance } \\
\text { between } \\
\text { holes, a, m }\end{array}$ & $\begin{array}{c}\text { Specific con- } \\
\text { sumption Of } \\
\text { Explosives, } q \text {, } \\
\mathrm{kg} / \mathrm{m}^{3}\end{array}$ & $\begin{array}{c}\text { the } \\
\text { utiliza- } \\
\text { tion } \\
\text { factor of } \\
\text { the } \\
\text { length of } \\
\text { the hole }\end{array}$ & $\begin{array}{c}\text { Waste } \\
\text { of rock } \\
\text { mass, } \\
L, \mathrm{~m}\end{array}$ \\
\hline \multicolumn{7}{|c|}{ The slope of the face to the layering $\alpha=30^{\circ}$} \\
\hline 1 & 0,038 & 1,4 & 0,30 & 2,80 & 0,85 & 10 \\
\hline 2 & 0,038 & 1,4 & 0,20 & 2,60 & 0,90 & 12 \\
\hline 3 & 0,038 & 1,4 & 0,37 & 3,00 & 0,80 & 9 \\
\hline 4 & 0,038 & 1,4 & 0,31 & 2,85 & 0,85 & 7 \\
\hline 5 & 0,038 & 1,4 & 0,21 & 2,55 & 0,90 & 10 \\
\hline \multicolumn{7}{|c|}{ The slope of the face to the layering $\alpha=60^{\circ}$} \\
\hline 1 & 0,038 & 1,4 & 0,30 & 3,00 & 0,86 & 10 \\
\hline 2 & 0,038 & 1,4 & 0,27 & 2,80 & 0,90 & 12 \\
\hline 3 & 0,038 & 1,4 & 0,32 & 3,20 & 0,82 & 9 \\
\hline 4 & 0,038 & 1,4 & 0,35 & 3,10 & 0,85 & 8 \\
\hline 5 & 0,038 & 1,4 & 0,25 & 2,75 & 0,90 & 10 \\
\hline
\end{tabular}

A model of a structural-block medium with a secant position of the breaking line to the main crack system was used. In the first series of the experiment, the slope of the bump surface to the direction of the crack system was $30^{\circ}$, and in the second $-60^{\circ}$. 


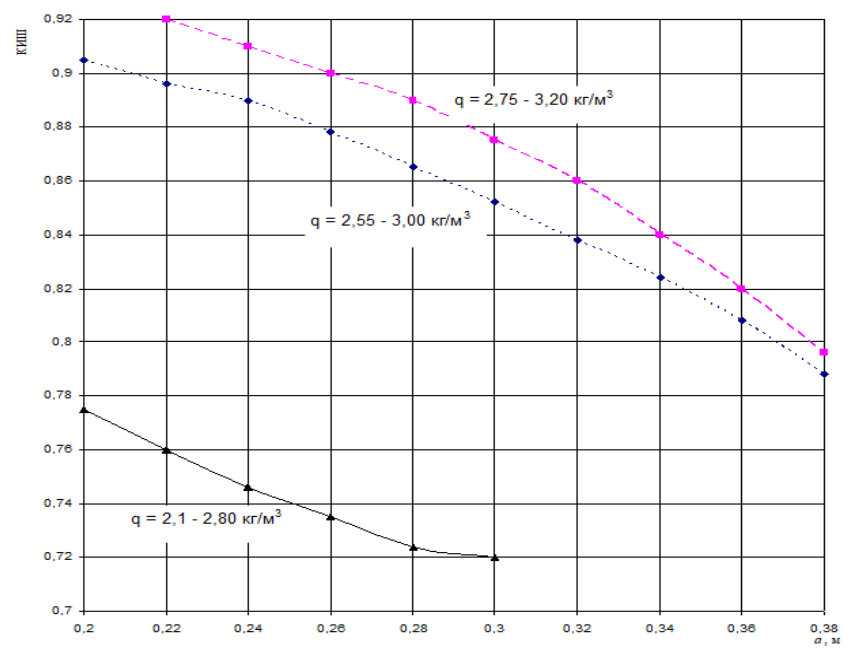

Fig. 6. Dependence of the utilization factor of the length of the hole (KISH) on the distance between the holes $(a)$

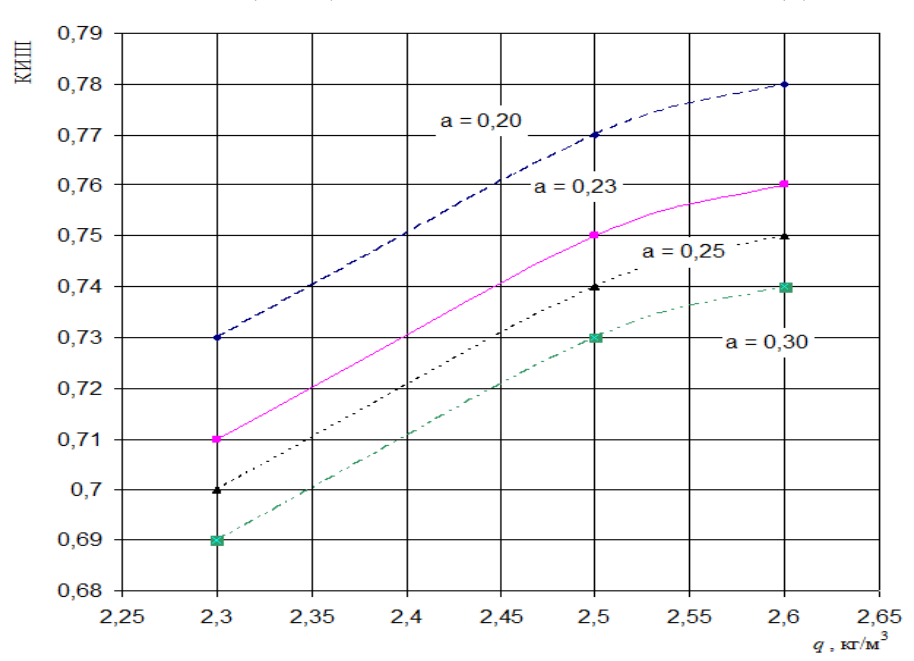

Fig.7. Dependence of the utilization factor of the length of the hole (KISH) on the specific consumption of explosives (q) at different distances between the holes 


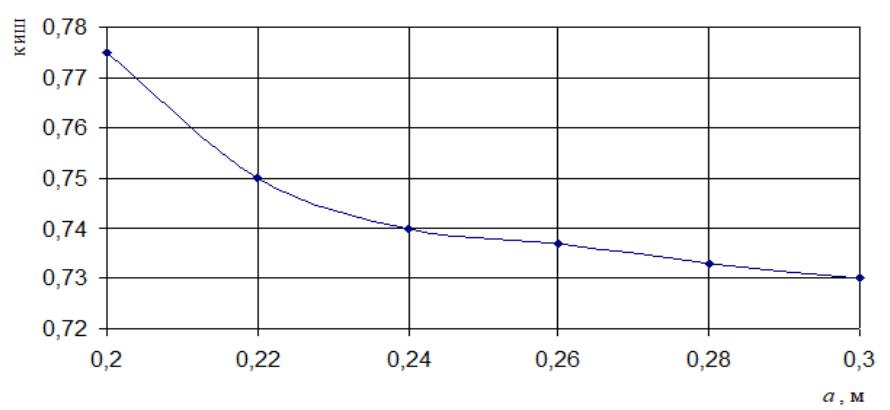

Fig.8. Dependence of the change in the utilization factor of the hole length on the distance between the holes when breaking rock mass in an array with normal fracturing to the face

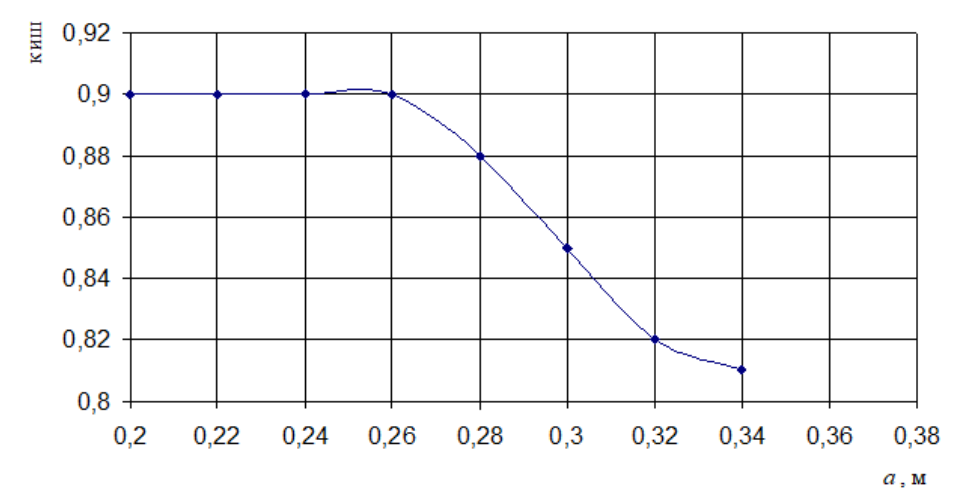

Fig. 9. Dependence of the change in the utilization factor of the hole length on the distance between the holes when breaking rock mass in an array with a slanting $\left(30^{\circ} \leq \alpha \leq 60^{\circ}\right)$ face fracturing

It is established that under these conditions the change of the distance between the holes from 0.20 to $0.27 \mathrm{~m}$ at the specific consumption of Explosives in the range of $2.55-2,80 \mathrm{~kg} / \mathrm{m}^{3}$ is stable level of utilization of the length of the hole in the explosion equal 0,90 (fig. 9).

Increase the distance between the holes to $0.30-0.37 \mathrm{~m}$, even when the corresponding increase in the specific consumption of Explosives to $3.0-3.2 \mathrm{~kg} / \mathrm{m}^{3}$ accompanied by a decrease of Kish, 0.80 is 0.86 . This result is explained by the fact that when the holes are extended by more than $0.30 \mathrm{~m}$, an uneven loading of the beaten array 
with explosion energy occurs and the interaction between adjacent explosive charges worsens.

\subsection{Investigation of the influence of drilling and blasting pa- rameters and fracturing of the massif on the lumpiness of the beaten ore}

In the work [18], a team of authors assesses the quality of ore crushing when wrapping on a clamping medium from collapsed rocks. The authors believe that with multi-row breaking with shortdelayed blasting, crushing is better than when breaking into an open space. With an increase in the number of beaten rows up to 5-7 or more, the crushing of ore worsens up to the camouflage drill holes. The displacement of the clamping material at the cleaning face reaches 2-3 $\mathrm{m}$, and the general compaction can be traced at a distance of up to 25-30 m.

A comparison of the quality indicators of explosive crushing of ore when breaking into an open space (chambers 1 and 3) and a clamping medium (chambers 5 and 7) produced in the same block showed that the specific consumption of explosives was 0.930 and $0.896 \mathrm{~kg} / \mathrm{t}$ in the first case, 0.778 and $0.837 \mathrm{~kg} / \mathrm{t}$ in the second case; the yield of oversized pieces, respectively, 8.5 and $9.8 \%$ and 4.4 and $6.8 \%$.

The ore bodies of the Yubileynoye deposit are characterized by a pronounced structural-block structure due to the fracturing of the meridional and north-eastern strike, as well as the presence of cleavage cracks. The ore strength reaches $12-15$ on the scale of M.M. Protodyakonov.

Due to such features of the structure of the ore bodies of the deposit, the impact of the diameter of wells, the grid of wells and the specific consumption of explosives on the rebound on the lumpiness of the beaten ore was determined in rocks of various fractures.

The ultimate goal of the research was to find the optimal parameters of drilling and blasting operations and develop recommendations for their calculation. The optimality criterion was the cost of $1 \mathrm{~m}^{3}$ of ore during extraction.

During the experimental-industrial explosions were recorded:

- consumption of explosives for rebounding and secondary crushing;

- output of oversized pieces and their dimensions; 
- the amount of beaten and unloaded ore;

- labor costs for drilling wells, their loading and blasting, release and loading of ore;

- CULH.

The volume of oversized ore after each explosion was determined by direct measurement of the pieces that did not pass through the screen. The degree of ore crushing during blasting was established by determining the yield of oversized pieces and distributing them by size classes. The productivity of the worker at the output was determined on the basis of time-lapse observations of the distribution of working time and the volume of ore released for each shift.

When planning research, it was important to reasonably determine the required number of experiments and evaluate the reliability of observations. In order to determine a sufficient number of experimental explosions and to establish the degree of variation of experimental data, pilot explosions were carried out, the measurement and calculation data for which are presented in Table 7.

The calculation of normalized indicators for the statistical evaluation of the output of the oversized during explosive ore stripping is given below.

The average value of the oversized output is

$$
\bar{\chi}=\frac{\sum \chi_{i}}{n}=\frac{62,9}{7}=8,98 \%
$$

where $\bar{\chi}$ - the arithmetic mean of the variation series, that is, the average value of the relative output of the oversized;

$\sum \chi_{\mathrm{i}}$ - the total value of the oversized output for all explosions;

$\sum \chi_{\mathrm{i}}=62,9$;

$n$ - number of explosions, $n=7$.

The standard deviation was determined by the formula

$$
\sigma=\sqrt{\frac{1}{n-1}\left[\sum \chi_{i}^{2}-\frac{\left(\sum \chi_{i}\right)^{2}}{n}\right]}=\sqrt{\frac{1}{6}\left[582,07-\frac{62,9^{2}}{7}\right]}=1,68
$$

Величина коэффициента вариации, выраженная в процентах от среднего значения исследуемого признака (выхода негабарита), вычисляется по формуле 


$$
K_{\text {sap }}=\frac{\sigma}{\chi} \cdot 100=\frac{1,68 \cdot 100}{8,98}=18,71 \% .
$$

The value of the coefficient of variation, expressed as a percentage of the average value of the studied feature (oversized output), is calculated by the formula

$$
K_{\text {sap }}=\frac{\sigma}{\chi} \cdot 100=\frac{1,68 \cdot 100}{8,98}=18,71 \% .
$$

The error of the arithmetic mean from its true value was

$$
\sigma_{\bar{\chi}}= \pm \frac{\sigma}{\sqrt{n}}= \pm \frac{1,68}{\sqrt{7}}= \pm 0,63
$$

The boundary of the confidence interval for the arithmetic mean with probability $p=0,9$ is determined by the dependence

$$
\Delta \chi= \pm \frac{\tau \sigma}{\sqrt{n}}= \pm \frac{1,9 \cdot 1,68}{\sqrt{7}}= \pm 1,21 .
$$

where $\tau$ - is the Student's coefficient for the number of observations equal to 7 (taken from the tables).

Thus, with a probability of 0.9 , it can be argued that the expected value of the oversized output is within $8.98 \pm 1.21 \%$, that is, it will not differ from the average value by more than $1.2 \%$.

The required number of experimental explosions for a given reliability and a calculated coefficient of variation equal to $18.71 \%$ will be

$$
n=t^{2} \cdot \frac{K_{\text {sap }}^{2}}{K_{\partial o n}^{2}}=1,65^{2} \cdot \frac{18,71^{2}}{15^{2}}=4,23 \approx 4 .
$$

where $K_{\partial o n}$ - the permissible error, the value of which for production and research work is usually assumed to be equal to $15 \%$;

$t$ - the normalized deviation with the specified reliability equal to 0.9 .

An analysis of the data in Table 7 shows that the data on the specific costs of explosives for secondary crushing have the greatest variation in the production of explosions. The required number of experiments to obtain reliable values for this feature is 9 , since the share of explosives costs during secondary burying in the total cost of mining 1 ton of ore is small, the minimum number of explosions to obtain reliable data, equal to 6 , was taken at the output of the oversized.

\begin{tabular}{l|l|l|l|l|l}
\hline$W=1,8$ & 2,0 & 2,2 & 2,3 & 2,4 & 2,5 \\
\hline
\end{tabular}




\begin{tabular}{l|c|c|c|c|c}
\hline$K=6,4$ & 8,0 & 8,4 & 9,3 & 9,5 & 11,8 \\
\hline$q_{1}=0,430$ & 0,422 & 0,478 & 0,478 & 0,420 & 0,478 \\
\hline$q_{2}=0,314$ & 0,324 & 0,505 & 0,446 & 0,515 & 0,548 \\
\hline$d_{c p}=72$ & 70 & 68 & 88 & 84 & 70 \\
\hline
\end{tabular}

With a change in the $1 \mathrm{lr}$ from 1.8 to $2.5 \mathrm{~m}$, there is a noticeable increase in the yield of oversized from 6.4 to $11.8 \%$, and, accordingly, an increase in the consumption of explosives for secondary crushing of oversized pieces of ore from 0.314 to $0.548 \mathrm{~kg} / \mathrm{m}^{3}$, there is a tendency to increase the average size of an oversized piece from 0.7 to $0.9 \mathrm{~m}$.

Fig. 10,11 shows graphs of empirical dependences of the change in the output of the oversized and the consumption of explosives for secondary crushing from the line of least resistance.

Table 7

Results of experimental explosions in panel 281

\begin{tabular}{|c|c|c|c|c|c|c|}
\hline \multirow[b]{2}{*}{$\begin{array}{c}\text { Explosion } \\
\text { numbers }\end{array}$} & \multicolumn{2}{|c|}{ Grid of wells } & \multirow[b]{2}{*}{$\begin{array}{c}\text { Oversize } \\
\text { d output } \\
\text { K, \% }\end{array}$} & \multirow[b]{2}{*}{$\begin{array}{l}\text { Specific } \\
\text { consump- } \\
\text { tion of } \\
\text { explosives } \\
\text { for primary } \\
\text { rebound, } \\
\mathrm{kg} / \mathrm{t}\end{array}$} & \multirow[b]{2}{*}{$\begin{array}{l}\text { Specific } \\
\text { consump- } \\
\text { tion of } \\
\text { explosives } \\
\text { for second- } \\
\text { ary crush- } \\
\text { ing, } \mathrm{kg} / \mathrm{M}^{3}\end{array}$} & \multirow{2}{*}{$\begin{array}{c}\text { The } \\
\text { average } \\
\text { diameter } \\
\text { of an } \\
\text { over- } \\
\text { sized } \\
\text { piece, } \\
\mathrm{cm}\end{array}$} \\
\hline & $\begin{array}{l}\text { the line of } \\
\text { least } \\
\text { re- } \\
\text { sistance, } \\
\text { (LLR) }\end{array}$ & $\begin{array}{c}\text { Distanc } \\
\mathrm{e} \\
\text { between } \\
\text { wells, } \mathrm{m}\end{array}$ & & & & \\
\hline I & 2,4 & 2,2 & 9,1 & 0,506 & 0,281 & 95 \\
\hline II & 1,8 & 1,8 & 6,4 & 0,430 & 0,314 & 72 \\
\hline III & 2,0 & 1,8 & 8,0 & 0,422 & 0,324 & 70 \\
\hline IV & 2,2 & 2,0 & 8,4 & 0,478 & 0,505 & 68 \\
\hline V & 2,3 & 2,1 & 9,3 & 0,478 & 0,446 & 88 \\
\hline VI & 2,5 & 2,2 & 11,8 & 0,478 & 0,548 & 70 \\
\hline VII & 2,4 & 2,1 & 9,9 & 0,420 & 0,515 & 84 \\
\hline$\Sigma$ & 15,60 & 14,20 & 62,9 & 3,212 & 2,933 & 547 \\
\hline Average & 2,23 & 2,03 & 8,98 & 0,459 & 0,419 & 78,14 \\
\hline $\begin{array}{l}\text { Coeffi- } \\
\text { cient }\end{array}$ & & & & & & \\
\hline of varia- & 1 & & & & & \\
\hline tion, $K_{\text {var }}$ & 1,21 & 8,37 & 18,70 & 6,10 & 26,25 & 13,71 \\
\hline$\sigma$ & 0,25 & 0,17 & 1,68 & 0,028 & 0,110 & 10,71 \\
\hline$\Delta \chi$ & 0,18 & 0,12 & 1,21 & 0,020 & 0,079 & 7,69 \\
\hline$n$ & 2 & 1 & 4 & 1 & 9 & 3 \\
\hline
\end{tabular}




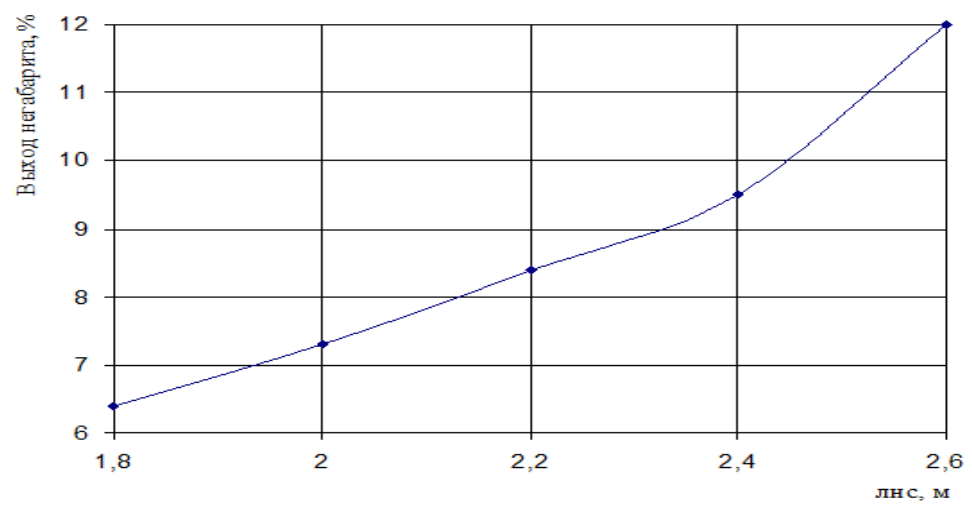

Fig. 10. Dependence of the oversized output $(+0.400 \mathrm{~m})$ on the $1 \mathrm{lr}$

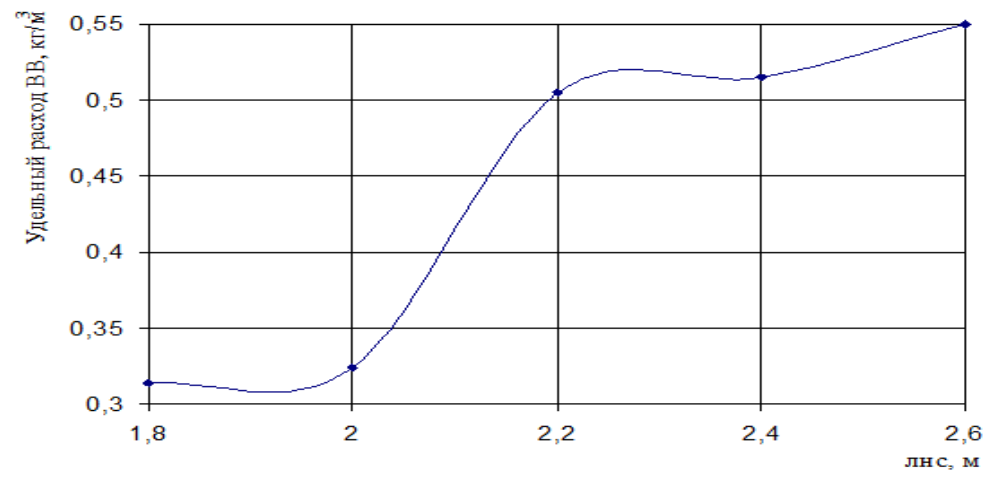

Fig. 11. Dependence of the specific consumption of explosives for secondary crushing on the llr

The adhesion along the cracks that separate natural rocks in the massif is no more than $2-3 \%$ of the adhesion of the rock in the monolith. Therefore, although the average size of natural separations in the ore massif is in the range of 250-300 $\mathrm{mm}$, the effect of explosive stress waves does not always cause the destruction of the rock along all cracks, and sometimes only along cracks forming large chunks represented by several undiscovered during the breaking of the separations.

The curve of the dependence of the number of pieces larger than $1000 \mathrm{~mm}$ on the LLR is shown in Fig. 12, from which it can be seen that with an increase in the LLR, with relatively identical specific 
costs of explosives, the output of large pieces, as well as the output of oversized, also increases. When blasting the fans of wells, the same specific consumption of explosives with an increase in LLR is achieved by a higher concentration of the mass of explosives being exploded simultaneously. This naturally causes an increased seismic effect of the explosion and the chipping of the massif over the drilling output.

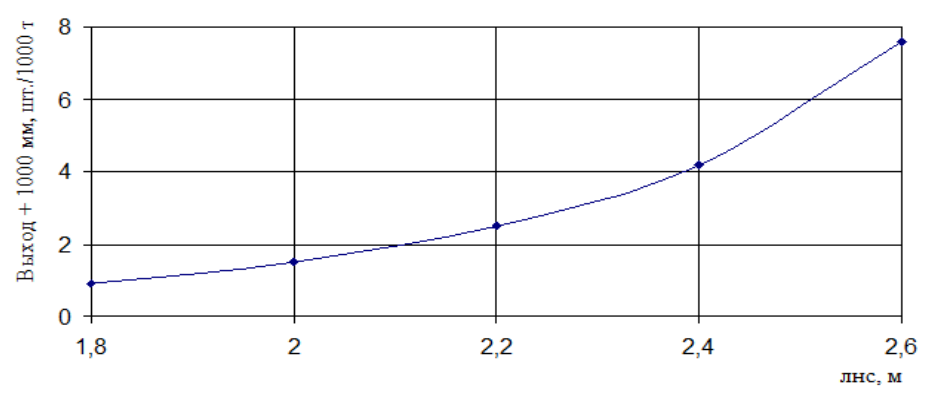

Fig. 12. Dependence of the yield of ore pieces with a grain size of $+1000 \mathrm{~mm}$ on changes in $1 \mathrm{lr}$

Fig. 13 shows the dependence of the specific consumption of explosives for secondary crushing, depending on the size of a substandard piece of ore.

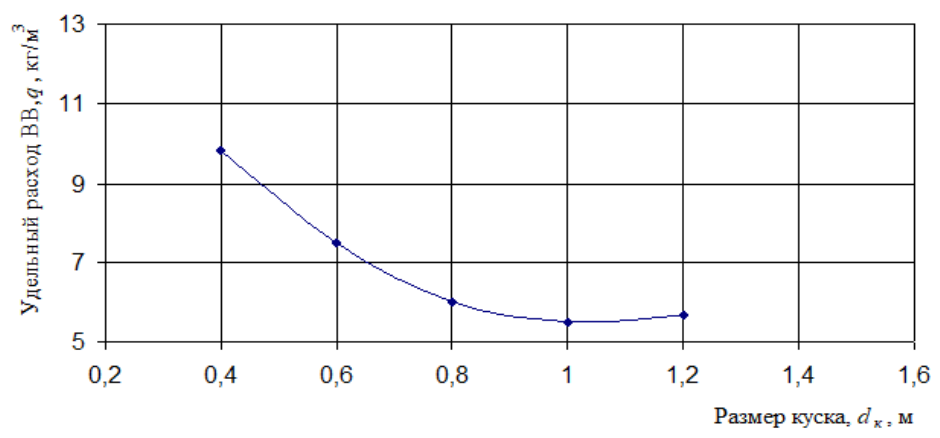

Fig. 13. Dependence of explosive consumption per $1 \mathrm{~m}^{3}$ during secondary crushing

Thus, both the size of the natural separation and the parameters of the cracks - their width and length - affect the results of crushing during chipping. When choosing the parameters of drilling and blasting operations, it is important to correctly assess their impact. The proposed method of frac- 
ture assessment based on the dynamic characteristics of elastic waves allows not only to determine the average size of the natural separation, but also to characterize the quality of cracks.

As a result of experimental and industrial work, it was found that part of the oversized pieces consists of a whole number of structural blocks, since the explosion energy is not enough to break the continuity of cracks in these pieces. This conclusion is confirmed by the results of laboratory experiments, which were discussed above.

Fig. 14 shows the dependence of the shift productivity of the LDM LC on loading and delivery of ore on the change in the output of the oversized in the beaten ore. Empirical data are described quite satisfactorily by an equation of the form, $\mathrm{m}^{3} /$ shift

$$
Q=\frac{C}{K+b},
$$

where $Q$ - ore output and delivery capacity, $\mathrm{m}^{3} /$ shift;

$K$ - the output of the oversized in the beaten ore, $\%$;

$C$ and $b$-empirical coefficients for the conditions of the «Molodezhny» mine $C=750, b=10$.

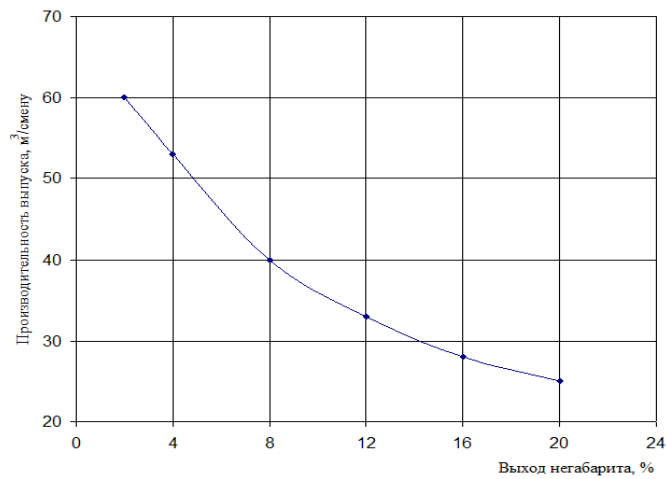

Fig. 14. Graphs of the dependence of the worker's productivity on the output of ore from the output of the oversized

\subsection{Recommended methods of breaking rock mass in a struc- turally block ore-containing array}

Based on the analysis of the world experience in the application of a mining system with a sub-storey collapse of ore and overlying 
rocks in the variant with the removal of ore in the clamp on collapsed rocks and the end release of ore mass to the drilling, based on the results of experimental studies, it is recommended to implement the following recommendations in production.

Taking into account the structural-block nature of the ore massif being worked out with the size of natural separations of $25-30 \mathrm{~cm}$, with sufficiently closed and coherent fracturing, it is advisable to increase the size of the conditioned piece of the beaten ore to the maximum extent possible. There is an opinion that during the breaking of the fractured rock mass is destroyed with the release of natural separations and the granulometric composition of the beaten ore is largely predetermined by the size of these separations. However, practice shows that even when breaking ore from fractured massifs with individual sizes of $20-25 \mathrm{~mm}$, there is an output of oversized pieces with dimensions exceeding 1.2-1.5 m and even more. Obviously, this is due to the fact that the chipped oversized piece of rock mass contains several natural separations that were not separated during the explosion.

A recognized direction in world practice for improving the efficiency of drilling and blasting operations is to increase the size of the conditioned piece at the strike to $1.2 \mathrm{~m}$. Increasing the size of the conditioned piece at the mines of Kazzinc JSC, Kazchrome JSC, Kazakhmys LLP allowed to reduce the yield of nega-barite from 20$25 \%$ to $5-7 \%$. At the same time, the local cost of ore extraction is reduced by $50-75 \%$ due to an increase in labor productivity at the ore output and an improvement in labor conditions due to a sharp reduction in the volume of secondary crushing of ore with overhead explosive charges. Crushing plants are equipped in underground chambers or on the surface of mines to meet the needs of the consumer in the rate of ore with a size of no more than $400 \mathrm{~mm}$.

The energy intensity of rock destruction during drilling and blasting of ore at iron ore quarries in Russia is estimated at $0.7-1 \mathrm{~kW} . \mathrm{h} / \mathrm{t}$, in the dry shops of processing plants $0.8-2.5 \mathrm{~kW} . \mathrm{h} / \mathrm{t}$. At the same time, the lower level of energy consumption during crushing obviously refers to the stage of large crushing, when pieces of 900-1200 $\mathrm{mm}$ in size are disintegrated to a size of $250-300 \mathrm{~mm}$. Thus, largescale crushing of rock pieces in crushers is quite comparable in energy costs with explosive breaking of rock mass, which is quite under- 
standable, since in both cases, large pieces are separated mainly by cracks of natural separations.

The reference book [19] provides an empirical relationship, proven by practice and recommended for calculations, between the maximum size of a piece of chipped rock mass $D_{\max }$ and the bucket capacity of the loading machine $V$, M

$$
D_{\max } \leq 0,75 \sqrt[3]{V}
$$

And a similar ratio between the maximum size of a piece of transported rock mass and the capacity of the transport vessel, $\mathrm{M}$

$$
D_{\max } \leq 0,5 \sqrt[3]{V}
$$

Taking into account the parameters of the LC-1 loading and delivery machine used at the Jubilee mine, it is advisable to switch to the size of the conditioned piece, determined based on the dependence (40), $\mathrm{M}$

$$
D_{\text {конд }}=0,5 \sqrt[3]{V}=0,5 \sqrt[3]{2}=0,63 \approx 0,6
$$

Conducting blasting operations with large specific explosive costs of the order of $2.0-2.4 \mathrm{~kg} / \mathrm{m}^{3}$ leads to deterioration of the stability of workings, greater dilution of ore, deterioration of the composition of the mine atmosphere, etc. Therefore, many foreign mines carry out blasting operations with small specific costs of Explosives:

Cleveland Mine (Canada)

Copper Cliff Court (Canada)

Dumbarton (Canada)

Meggen (Germany)

Mount Isa (Australia)

Minddelplatz (Germany)

Vihanti (Finland)
Specific consumption of explosives, $\mathrm{kg} / \mathrm{t}$

$$
\begin{gathered}
0,28-0,42 \\
0,6 \\
0,27 \\
0,2-0,5 \\
0,2-0,27 \\
0,33 \\
0,2
\end{gathered}
$$

When working with such a specific consumption of explosives, the size of the conditioned piece at the ore output is taken at the level of 600-800 mm, and at a number of mines $900-1000 \mathrm{~mm}$. To ensure normal loading conditions for transport and lifting vessels, the mines are equipped with precinct crushing complexes. The productivity of crushing complexes varies from 250 to $600 \mathrm{t} / \mathrm{h}$. The size of crushed ore is usually minus $130-150 \mathrm{~mm}$. The use of such an ore extraction technology leads to a reduction in costs by 0.4-0.5 USD/t [20]. 
To bring the requirements of ore consumers into line with the actual lumpiness of the ore mass, it is advisable to install a jaw or cone crusher with a $600 \times 900 \mathrm{~mm}$ intake opening on the mine site, or, taking into account the possibility of switching to more powerful mining equipment in the future, increase the intake opening of the crusher to $900 \times 1200 \mathrm{~mm}$.

Based on experimental work to establish the dependence of the utilization coefficient of the length of wells on influencing factors when conducting ore stripping in a structural block array, with the actual orientation of the main system of cracks in the plane of the strike of the ore bodies of the deposit, it is advisable to deploy the position of the surface of the ore stripping at an angle of $60^{\circ}$ to the axis of the drilling. To do this, it is recommended to switch to the removal of the cleaning layer with two half-veers of wells with the addition of a convex shape to the bottom of the face. According to the practice of the mines of the Kiruna iron ore basin (Sweden), this form of treatment face will additionally provide an improvement in the output of beaten ore for drilling [24].

V.I. Mashukov also believes that when drilling into the clamping medium, wells should be located according to a radially convex scheme [23].

\section{Conclusion}

1. When assessing the fracturing parameters of the ore-containing massif of the Yubileyny mine by measuring the amplitude of displacements in the rock mass during the passage of elastic waves generated by the explosion of calibrated explosive charges, it was found that the average size of the natural separations released by cracks is $345 \mathrm{~m}-25 \mathrm{~cm}$, and $331 \mathrm{~m}-32 \mathrm{~cm}$.

2 . The search of rock during the contouring of workings by blasting, first of all, is determined by the distance between the holes (wells) and the line of least resistance, and only then by the specific flow rate of explosives. The use of dispersed charges in contouring holes makes it possible to reduce the amount of rock sorting by an order of magnitude compared to solid charges.

3 . The coefficient of use of the hole when breaking rock mass in a structural block array significantly depends on the orientation of the surface of the treatment face relative to the main system of cracks. At 
the normal intersection of orthogonal natural separations with the surface of the chipping front, the utilization factor of the boreholes is 0.72-0.80, and when the orientation of the cleaning face changes at an angle of $30^{\circ}$ or $60^{\circ}$, it increases to 0.90 with sufficient density of boreholes on the face surface.

4. The lumpiness of the chipped rock mass is determined primarily by the ratio of the distance between the explosive charges and the size of the natural separation, the output of oversized pieces of ore is significantly determined by the established size of the conditioned piece, With a uniform distribution of explosive charges in the destroyed volume of the array and with an increase in the size of the conditioned piece size to $600 \mathrm{~mm}$, the output of oversized pieces in the chipped rock mass can decrease to $4-5 \%$.

\section{List of sources used}

1. Phillipov V.K., Aliev D.K. Razrusheniye krepkih porod pri razlichnyh sposobav vzryvanya. Alma-Ata: Nauka, 1973.-80s

2. Resultati issledovanyi po intensifikacy droplenya gornyh porod $\mathrm{v}$ uslovyah mednorudnyh karerov Urala.V.P. Ulybin,A.A Betmanova , G.V. Kuznetsov,S.V.Gubanov // Pervaya nauchno-tecgnicheskaya konferencya po sovershenstvovanyu burovzryvnih rabot na karerah tsvetnoy metallurgiy Urala. Sverdlobsk; UNIPROmed._1970._s.124-138.

3. Zaks L.Statisticheskyh ocevanye.M.:Statistika,1976.-599s $128 \mathrm{~s}$

4. Quen U. Opisatelnaya I induktivnaya statistika. M.: Financi I statistika, 1981-

5. Kolkot E. Proverka znachimosti. M.: Statistika, 1978.-128s

6. Finkel V.M. Physika razrushenya. Rost treshin $\mathrm{v}$ tverdih telah. M.:Metallurgiy,1970-376s.

7. Radenko E.S. issledovanye osnovnyh voprosov podzemnoy razrabotki sblizhennih zalezhei zhezkazganskogo mestorozhdenya: avtoreph kand. tech.nauk:Tashkent:TPY,1966-23S.

8. Borsh-Kompiec V.I. Mechanika gornyh porod, massivov I gornoe davlenye. M.:Izdanye MGI, 1968-484s.

9. Physenko G.L. Metody kolichestvennoy otsenki structurnyh oslableniy massiva gornyh porod v svyezi s analizom ix ustoichivosti/ Vtoraya vsesoyuznaya konferencia <<Sovremennye problemi mechaniki gornyh porod. L.: 1982.-S. 21-29.

10. Baklanov I.V., Kartozya B.A. Mechanika gornyh porod.M.:Nedra,1975271S.

11. Prochnost I deformiruemost gornyx gornyh porod/U.M. Kartashov,B.V. Matveev, G.v.Micheev, A.B.Phadeev. M: Nedra,1979.-269s.

12. Kim D.N. Issledovanie structurnogo oslablenye treshinovatih porod modelirovanya prochnostnyh svoistv v laboratornih usloviyah/ Tr. IGD UF AN SSSR. Sverdlovsk, st/№ 5, 1963.-S. 97-105. 
13. Povishenye effectivnosti I bezopasnosti burovzrivnyh rabot / I.M. Murzikov,Es. Gorev, V.I/ Lantev,A.N.Zamotaev// Tsetnaya metallurgiya/-1990. № $5 .=$ C. $1-5$.

14. Turchaninov I.A., Iosiv M.A., Kasparyan E.V. Osnovi mechaniki gornyh porod.L.:Nedra,1977.-503s.

15. Mashanov A.A Treshinovatost gornyh porod.Almaty, 2000.-124c.

16. Mostkov V.M. Podzemnye sooruzhenya bolshogo sechenya.M.:Nedra,1974.-320s.

17. Erofeev I.E. povizenye effectivnosti burovzrivnih rabot na rudnikah.M.:Nedra,1988.-271s.

18. Sovershenstvovanye metodov podzemnoy razrabotki Ziryanovskogo mestorozhdenya. Collectiv avtorov. Alma-Ata: Kazakhstan,1975.-384s.

19. Spravochnik. Otkrytie gornyh raboti. M.;Gornoe byuro, 1994.-512s.

20 Airapetyan L.G., Bogolubov A.A. Analiz issledovanya uchastkovih drobilnih kompleksov na podzemnih rudnika// Tsvetnaya metallurgiya.-1990, №.-S.8587.

21. Bronikov D.M., Vanesov N.F., Bogdanov G.I. Razrabotka rud na bolshih glubinah . M.; Nedra, 1982.-292s.

22. Rikovskyi B.B., Batuev M.A., Hudov S.V., Dubskih A.V Burimost I vzrivaemost piroksenitov Gusevogorskogo mestorozhdenya// Gornyi jurnal/-1991, №S.59-60

23. Mashukov V.I. Deistvie vzriva na okruzhayushuyu sredu I sposoby upravlenya im. M.;Nedra,1976.-248s.

24. Stazhevskyi S.B., Phreidin A.M. Rusin E.P. Na podzemnih rudnikah Swetci ( Sostoyanye I perspektivy)// Gorniy jurnal/-1991, № 10, S. 55-59.

https://doi.org/10.31713/m1114

\title{
RESOURCE-SAVING CONTROL SYSTEMS FOR ELECTRIC DRIVES OF MODERNIZED DRILL RIGS FOR OPEN-MINES OF UKRAINE
}

\author{
Khilov V.S. \\ Dnipro University of Technology. \\ Doctor of Technical Sciences, Professor, Ukraine
}

\begin{abstract}
A comparative analysis of the characteristics of DRGs used in opencast mining in Ukraine is given. Experimental studies of the influence of drive systems and drill rigs on the dynamics of the drill process were carried out in the mining and geological conditions of the Central Mining and Processing Plant (Kryvyi Rih, Ukraine). Frequency characteristics and analysis of dynamic properties of automated drive systems and frequency characteristics of transmissions of the rotation
\end{abstract}

